OPEN ACCESS

Edited by:

Brigitte Mauch-Mani,

University of Neuchâtel, Switzerland

Reviewed by:

Roland Wohlgemuth,

Sigma-Aldrich, Switzerland

James Moir

University of York, United Kingdom

${ }^{*}$ Correspondence:

Ji-Gang Bai

baijg73@163.com;

baijg@sdau.edu.cn

tThese authors have contributed equally to this work.

Specialty section: This article was submitted to Plant Microbe Interactions, a section of the journal

Frontiers in Microbiology

Received: 12 February 2018 Accepted: 24 May 2018

Published: 14 June 2018

Citation:

Wu F, An Y-Q, An Y, Wang X-J,

Cheng $Z-Y$, Zhang $Y$, Hou $X$,

Chen $C-X$, Wang $L$ and Bai J-G (2018) Acinetobacter calcoaceticus CSY-P13 Mitigates Stress of Ferulic and p-Hydroxybenzoic Acids in Cucumber by Affecting Antioxidant

Enzyme Activity and Soil Bacterial Community. Front. Microbiol. 9:1262. doi: 10.3389/fmicb.2018.01262

\section{Acinetobacter calcoaceticus CSY-P13 Mitigates Stress of Ferulic and $p$-Hydroxybenzoic Acids in Cucumber by Affecting Antioxidant Enzyme Activity and Soil Bacterial Community}

\author{
Fenghui Wu ${ }^{1,2 t}$, Yan-Qiu An ${ }^{1 \dagger}$, Yanrong An ${ }^{1+}$, Xiu-Juan Wang ${ }^{1+}$, Zeng-Yan Cheng ${ }^{1}$, \\ Yue Zhang ${ }^{1}$, Xinwei Hou ${ }^{1}$, Chang-Xia Chen ${ }^{1}$, Li Wang ${ }^{1}$ and Ji-Gang Bai' ${ }^{1 *}$
}

'State Key Laboratory of Crop Biology, College of Life Sciences, Shandong Agricultural University, Tai'an, China, ${ }^{2}$ State Key
Laboratory of Crop Biology, College of Horticulture Science and Engineering, Shandong Agricultural University, Tai'an, China

Ferulic acid (FA) and p-hydroxybenzoic acid (PHBA) are main phenolic compounds accumulated in rhizosphere of continuously cropped cucumber, causing stress in plants. Microbial degradation of a mixture of FA and PHBA is not well understood in soil. We isolated a strain CSY-P13 of Acinetobacter calcoaceticus, inoculated it into soil to protect cucumber from FA and PHBA stress, and explored a mechanism underlying the protection. CSY-P13 effectively degraded a mixture of FA and PHBA in culture solution under conditions of $39.37^{\circ} \mathrm{C}, \mathrm{pH} 6.97$, and $21.59 \mathrm{~g} \mathrm{~L}^{-1}$ potassium dihydrogen phosphate, giving rise to 4-vinyl guaiacol, vanillin, vanillic acid, and protocatechuic acid. During FA and PHBA degradation, activities of superoxide dismutase (SOD), catalase, ascorbate peroxidase, and dehydroascorbate reductase in CSY-P13 were induced. Inoculated into cucumber-planted soil containing $220 \mu \mathrm{g} \mathrm{g}^{-1}$ mixture of FA and PHBA, CSY-P13 degraded FA and PHBA in soil, increased plant height, and decreased malonaldehyde, superoxide radical, and hydrogen peroxide levels in leaves. CSY-P13 also enhanced SOD, guaiacol peroxidase, catalase, glutathione peroxidase, ascorbate peroxidase, monodehydroascorbate reductase, dehydroascorbate reductase, and glutathione reductase activities; increased ascorbate and glutathione contents; and elevated transcript levels of copper/zinc SOD, manganese SOD, and catalase in leaves under FA and PHBA. Moreover, CSY-P13 increased phosphatase, catalase, urease, and sucrase activities and changed bacterial richness, diversity, and community composition by high throughput sequencing in cucumber-planted soil supplemented with the mixture of FA and PHBA. So CSY-P13 degrades the mixture of FA and PHBA in soil and mitigates stress from the two phenolic compounds in cucumber by activating antioxidant enzymes, changing soil bacterial community, and inducing soil enzymes.

Keywords: Acinetobacter calcoaceticus, antioxidant enzyme, bacterial community, cucumber, ferulic acid, p-hydroxybenzoic acid 


\section{INTRODUCTION}

Many crops including cucumber are often grown repeatedly in a same soil in intensive agriculture. As a result, phenolic compounds secreted by crop roots are accumulated in the soil. The accumulation of these phenolic compounds has allelopathic stress effects and can inhibit plant growth and development, thereby restraining sustainable crop production (Yu, 2001). When cucumber plants have been continuously cropped for 7 years, ferulic acid (FA) and p-hydroxybenzoic acid (PHBA, 4-hydroxybenzoic acid) are the main phenolic compounds, which are accumulated in rhizospheric soil (Xu S.X. et al., 2008). Therefore, degrading a mixture of FA and PHBA in soil may mitigate the allelopathic stress effects of accumulated phenolic compounds on crops such as cucumber.

Microbial degradation of phenolic compounds (Yu, 2001) is cost-effective and environmentally friendly (De et al., 2006). Strain 11 of Acinetobacter calcoaceticus is able to utilize a phenolic mixture of PHBA, 2-hydroxybenzoic acid, and 3-hydroxybenzoic acid in medium (Prathibha and Sumathi, 2008). A. calcoaceticus DSM586 can grow on PHBA as sole carbon source and also has a capacity of degrading FA in medium (Delneri et al., 1995). Using Acinetobacter sp. PK1, phenolic compounds including FA and PHBA are removed from palm oil mill effluent (Khongkhaem et al., 2016). To the best of our knowledge, it has not been reported that strains of Acinetobacter might degrade a mixture of FA and PHBA in soil.

To deplete a mixture of FA and PHBA in soil and thereby to protect plants from the stress of the mixed phenolic compounds, a strain CSY-P13 was isolated from rhizospheric soil of continuously cropped cucumber and identified as A. calcoaceticus in this study. Then, we applied the strain CSY-P13 to cucumberplanted soil supplemented with a mixture of FA and PHBA. It was hypothesized that Acinetobacter strains obtained from continuous cropping soil might have a phenolic compounddegrading ability, thus decomposing a mixture of FA and PHBA in soil and protecting plants under phenolic compoundcontained conditions.

We next explored a mechanism underlying the protection effects of CSY-P13. Addition of FA (Zhang et al., 2015) or PHBA (Chen et al., 2015) to cucumber-planted soil causes oxidative stress in seedlings, which leads to overproduction of reactive oxygen species (ROS) including superoxide radical $\left(\mathrm{O}_{2}^{\bullet-}\right)$ and hydrogen peroxide $\left(\mathrm{H}_{2} \mathrm{O}_{2}\right)$. The overproduced ROS inhibits plant growth and even results in cell death (Wan et al., 2015). To control ROS levels, plants evolve an antioxidant system, in which superoxide dismutase (SOD, EC 1.15.1.1), guaiacol peroxidase (GPX, EC 1.11.1.7), catalase (CAT, EC 1.11.1.6), glutathione peroxidase (GSH-Px, EC 1.11.1.9), ascorbate peroxidase (APX, EC 1.11.1.11), monodehydroascorbate reductase (MDHAR, EC 1.6.5.4), dehydroascorbate reductase (DHAR, EC 1.8.5.1), and glutathione reductase (GR, EC 1.6.4.2) are common antioxidant enzymes, and ascorbate (AsA) and reduced glutathione (GSH) are important antioxidants (Zhang et al., 2012). SOD dismutates $\mathrm{O}_{2}^{\bullet-}$ into $\mathrm{H}_{2} \mathrm{O}_{2}$ and $\mathrm{O}_{2}$, and GPX, CAT, GSH-Px, and APX regulate $\mathrm{H}_{2} \mathrm{O}_{2}$ levels, while GSH-dependent DHAR and GR (an enzyme for GSH regeneration) and/or MDHAR regenerate AsA to act as a substrate for APX (Wan et al., 2015). In addition, phenolic compounds influence soil enzyme activities (Chen et al., 2015; Zhang et al., 2015) and change microbial communities in cucumber-planted soil (Zhou et al., 2012). Therefore, we determined antioxidant enzyme activities in cucumber, analyzed soil enzyme activities, and detected microbial communities in soil. Our hypothesis was that CSYP13 degraded a mixture of FA and PHBA in cucumberplanted soil, induced antioxidant enzymes in seedlings, activated soil enzymes, and changed microbial communities in soil, mitigating the stress of FA and PHBA in cucumber. Moreover, stress-responsive proteins in a phenol-degrading Acinetobacter strain contribute to the tolerance of this microorganism to phenol stress (Lin, 2017). During PHBA degradation, oxidative stress-responsive antioxidant enzymes are induced in a PHBAdegrading Pseudomonas due to exposure of this bacterium to PHBA (Chen et al., 2015). Thus, when CSY-P13 was used to degrade a mixture of FA and PHBA in this study, the activities of antioxidant enzymes in this strain were analyzed to investigate a degradation mechanism of CSY-P13.

\section{MATERIALS AND METHODS}

\section{Isolation, Identification, and Growth Conditions of Strain CSY-P13}

When cucumber has been continuously cropped for 3 years, a PHBA-degrading strain CSY-P13 was isolated from rhizosphere soil in late autumn of the third year by using M-9 medium (Turner and Rice, 1975) supplemented with $0.5 \mathrm{~g} \mathrm{~L}^{-1}$ PHBA according to Chen et al. (2015). To analyze the FA-degrading ability of CSY-P13, this strain was then inoculated into M-9 medium containing $0.5 \mathrm{~g} \mathrm{~L}^{-1} \mathrm{FA}$ (Zhang et al., 2015). After that, a fragment that targets 10 variable regions in the $16 \mathrm{~S}$ rRNA gene was amplified from CSY-P13 with the universal primers 1492R and 27F (Wang et al., 2011), and its sequence was deposited in GenBank under an accession number MG773121. By using the $16 S$ rRNA gene sequence, sequence alignment was conducted with the database of National Center for Biotechnology Information (NCBI), and phylogenetic analysis was performed with the Molecular Evolutionary Genetics Analysis (MEGA) 7.0 software package. Then, we analyzed the physiological and biochemical properties of CSY-P13, including nitrate reduction; indole production (Pagel and Seyfried, 1976); Gram staining (Buck, 1982); gelatin liquefaction; glucose fermentation (Bouvet and Grimont, 1986); motility; sucrase activity; utilization of citrate, mannitol, and glucose (Kim et al., 2008); and activities of catalase and oxidase (Lee and Lee, 2010). The strain CSY-P13 was identified based on the sequence alignment and phylogeny analysis of the 16S rRNA gene sequence, combined with the physiological and biochemical properties with reference to the Bergey's Manual of Determinative Bacteriology.

To incubate CSY-P13, the strain was cultured in Luria-Bertani (LB) liquid medium (containing $10 \mathrm{~g} \mathrm{~L}^{-1}$ tryptone, $5 \mathrm{~g} \mathrm{~L}^{-1}$ yeast extract, and $10 \mathrm{~g} \mathrm{~L}^{-1} \mathrm{NaCl}$ ) at $28^{\circ} \mathrm{C}$ and $180 \mathrm{rpm}$. Then, $1 \mathrm{~mL}$ of exponentially growing culture was inoculated into $100 \mathrm{~mL}$ of M-9 liquid medium in a 250-mL Erlenmeyer flask. Cell growth of 
CSY-P13 was measured by the optical density of culture solutions at $600 \mathrm{~nm}\left(\mathrm{OD}_{600}\right)$. The FA to PHBA ratio was 57.18: 42.82 $(\mathrm{w} / \mathrm{w})$ in a mixture of FA and PHBA in this study, with reference to the concentrations of FA (16.56 $\mathrm{gg} \mathrm{g}^{-1}$ soil) and PHBA (12.40 $\mathrm{\mu g} \mathrm{g}^{-1}$ soil) in rhizosphere soil, where cucumber has been continuously cropped for 7 years (Xu S.X. et al., 2008).

\section{Concentrations of FA and PHBA in Culture Solutions and Soil}

The concentrations of FA and PHBA in culture solutions and soil were determined using high performance liquid chromatography (HPLC) with an Agilent 1200 Rapid Resolution Liquid Chromatography system (Agilent Technologies, Germany) according to Chen et al. (2015) and Zhang et al. (2015).

\section{Properties of CSY-P13}

The properties of CSY-P13 were investigated by analyzing the percentages of degraded FA and PHBA in culture solutions with HPLC. To examine the optimum initial concentration of the mixture of FA and PHBA in the ratio of 57.18: 42.82, CSY-P13 was inoculated into M-9 medium supplemented with $0.1,0.2,0.3$, 0.4 , or $0.5 \mathrm{~g} \mathrm{~L}^{-1}$ mixture of FA and PHBA, and then incubated at $28^{\circ} \mathrm{C}$ and $180 \mathrm{rpm}$ for $6 \mathrm{~h}$. To detect the optimum nitrogen source, CSY-P13 was inoculated into M-9 medium, in which $0.2 \mathrm{~g} \mathrm{~L}^{-1}$ mixture of FA and PHBA (including $114.4 \mathrm{mg} \mathrm{L}^{-1}$ FA and $85.6 \mathrm{mg} \mathrm{L}^{-1}$ PHBA) was supplemented, and $1 \mathrm{~g} \mathrm{~L}^{-1}$ $\mathrm{NH}_{4} \mathrm{Cl}$ was changed into the same molar mass of nitrogen from $\left(\mathrm{NH}_{4}\right)_{2} \mathrm{SO}_{4}, \mathrm{NaNO}_{3}, \mathrm{NH}_{4} \mathrm{NO}_{3}$, or urea. Subsequently, the strain was incubated at $28^{\circ} \mathrm{C}$ and $180 \mathrm{rpm}$ for $6 \mathrm{~h}$. To identify the optimum culture temperature, CSY-P13 was inoculated into M-9 medium supplemented with $0.2 \mathrm{~g} \mathrm{~L}^{-1}$ mixture of FA and PHBA, and incubated for $3 \mathrm{~h}$ at $180 \mathrm{rpm}$ and different temperatures $\left(18,23,28,37,39,40,41,43\right.$, or $\left.45^{\circ} \mathrm{C}\right)$. To determine the optimum shaking speed, CSY-P13 was inoculated into M-9 medium supplemented with $0.2 \mathrm{~g} \mathrm{~L}^{-1}$ mixture of FA and PHBA, and incubated for $2.5 \mathrm{~h}$ at $40^{\circ} \mathrm{C}$ with shaking at different speeds $(130,160,180,200$, or $230 \mathrm{rpm})$. To measure the optimum $\mathrm{pH}$ for CSY-P13, M-9 medium was supplemented with $0.2 \mathrm{~g} \mathrm{~L}^{-1}$ mixture of $\mathrm{FA}$ and $\mathrm{PHBA}$, and its initial $\mathrm{pH}$ value was adjusted to different values $(4,5,6,7$, or 8 ) with $1 \mathrm{M} \mathrm{HCl}$ or $\mathrm{NaOH}$. Then, CSY-P13 was inoculated into this medium and incubated at $40^{\circ} \mathrm{C}$ and $180 \mathrm{rpm}$ for $2 \mathrm{~h}$. To analyze the optimum initial concentration of $\mathrm{KH}_{2} \mathrm{PO}_{4}$, CSY-P13 was inoculated into M-9 medium, in which $0.2 \mathrm{~g} \mathrm{~L}^{-1}$ mixture of FA and PHBA was supplemented, and the initial concentrations of $\mathrm{KH}_{2} \mathrm{PO}_{4}$ were changed into $10,20,30,40$, or $50 \mathrm{~g} \mathrm{~L}^{-1}$. After that, the strain was incubated at $40^{\circ} \mathrm{C}$ with shaking $(180 \mathrm{rpm})$ for $2 \mathrm{~h}$.

\section{Response Surface Optimization for FA and PHBA Degradation by CSY-P13}

On the basis of the properties of CSY-P13, $\mathrm{KH}_{2} \mathrm{PO}_{4}$ concentration, culture temperature, and $\mathrm{pH}$ were used to optimize the degradation of the mixture of FA and PHBA by Box-Behnken design. The experimental design with the levels and codes of independent variables is given in Supplementary
Table S1, and the predicted percentages of degraded FA and PHBA are shown in Supplementary Table S2.

\section{Antioxidant Enzyme Activities in CSY-P13}

CSY-P13 was inoculated into M-9 medium supplemented with $0.2 \mathrm{~g} \mathrm{~L}^{-1}$ mixture of FA and PHBA and incubated for $2 \mathrm{~h}$ under conditions optimized by the response surface methodology. As a control, CSY-P13 was inoculated into M-9 medium supplemented with $306.88 \mathrm{mg} \mathrm{L}^{-1}$ glucose, in which the numbers of carbon atoms were equivalent to those in $0.2 \mathrm{~g} \mathrm{~L}^{-1}$ mixture of FA and PHBA. Since $0.2 \mathrm{~g} \mathrm{~L}^{-1}$ mixture of FA and PHBA included $114.4 \mathrm{mg} \mathrm{L}^{-1} \mathrm{FA}$ and $85.6 \mathrm{mg} \mathrm{L}^{-1} \mathrm{PHBA}$, the strain CSY-P13 was also inoculated into M-9 medium supplemented with $114.4 \mathrm{mg} \mathrm{L}^{-1} \mathrm{FA}$ or $85.6 \mathrm{mg} \mathrm{L}^{-1} \mathrm{PHBA}$ as another two controls. When culture solutions were centrifuged at $4^{\circ} \mathrm{C}$ and $5000 \mathrm{~g}$ for $20 \mathrm{~min}$, cell pellets were collected and ground in liquid nitrogen. Then, cell powder $(0.1 \mathrm{~g})$ was soaked into $1 \mathrm{~mL}$ of $100 \mathrm{mM}$ potassium phosphate buffer ( $\mathrm{pH}$ 7.5) containing $1 \mathrm{mM}$ ethylenediaminetetraacetic acid (EDTA), $3 \mathrm{mM}$ DLdithiothreitol, and 5\% (w/v) polyvinylpolypyrrolidone (PVP) (Gratão et al., 2008). After centrifugation at $4^{\circ} \mathrm{C}$ and $10,000 \mathrm{~g}$ for $20 \mathrm{~min}$, the resulting supernatants were used to assay the activities of SOD, APX, CAT, and DHAR due to the reduction of nitroblue tetrazolium (NBT), oxidation of AsA, decompounding of $\mathrm{H}_{2} \mathrm{O}_{2}$, and formation of AsA, respectively (Zhang et al., 2012). One unit of SOD activity was defined as the amount of enzyme that gave $50 \%$ inhibition of NBT reduction. One unit of CAT, APX, and DHAR activity was defined as $1 \mu \mathrm{mol}$ of $\mathrm{H}_{2} \mathrm{O}_{2}$ consumed per minute, $1 \mu \mathrm{mol}$ of AsA oxidized in one minute, and $1 \mathrm{nmol}$ of AsA formed per minute, respectively.

\section{Degradation Products of FA and PHBA by CSY-P13}

CSY-P13 was inoculated into M-9 medium supplemented with $0.2 \mathrm{~g} \mathrm{~L}^{-1}$ mixture of FA and PHBA, $114.4 \mathrm{mg} \mathrm{L}^{-1} \mathrm{FA}$, or $85.6 \mathrm{mg} \mathrm{L}^{-1} \mathrm{PHBA}$, respectively. Then, the strain was incubated for $2 \mathrm{~h}$ under conditions optimized by the response surface methodology. The concentrations of degradation products from FA and PHBA by CSY-P13 were determined with HPLC according to Chen et al. (2015) and Zhang et al. (2015).

\section{Degradation of the Mixture of FA and PHBA in Soil}

In order to grow cucumber seedlings, soil with the following characteristics was autoclaved at $121^{\circ} \mathrm{C}$ for $20 \mathrm{~min}$ and then air-dried at $30^{\circ} \mathrm{C}$ until a constant weight was reached: $\mathrm{pH} 7.34$, $1.37 \mathrm{~g} \mathrm{~kg}^{-1}$ total $\mathrm{N}, 29.95 \mathrm{mg} \mathrm{kg}^{-1} \mathrm{NO}_{3}-\mathrm{N}, 13.87 \mathrm{mg} \mathrm{kg}^{-1} \mathrm{NH}_{4}{ }^{-}$ $\mathrm{N}, 20.96 \mathrm{mg} \mathrm{kg}^{-1}$ Olsen-P, $86.76 \mathrm{mg} \mathrm{kg}^{-1}$ rapidly available $\mathrm{K}$, $157.7 \mu \mathrm{s} \mathrm{cm}^{-1}$ electrical conductivity, and $0.75 \%$ organic matter. To apply CSY-P13 to soil, the strain was cultured in $100 \mathrm{~mL}$ of $\mathrm{LB}$ liquid medium at $28^{\circ} \mathrm{C}$ until $\mathrm{OD}_{600}=1$. Then, the culture solutions were centrifuged at $4^{\circ} \mathrm{C}$ and $5000 \mathrm{~g}$ for $20 \mathrm{~min}$. The resulting cell pellets were resuspended into autoclaved water to reach a concentration of $5.84 \log \mathrm{cfu} \mathrm{mL}^{-1}$. 
Each seed of cucumber (Cucumis sativus cv. Jinchun no. 4) was germinated at $25^{\circ} \mathrm{C}$ for 2 days, and then transferred to a $10-\mathrm{cm}$-diameter plastic pot containing $450 \mathrm{~g}$ of autoclaved soil. Having been grown at $25^{\circ} \mathrm{C}$ with a photoperiod of $12 \mathrm{~h}$ light $\left(600 \mu \mathrm{mol} \mathrm{m} \mathrm{m}^{-2} \mathrm{~s}^{-1}\right) / 12 \mathrm{~h}$ dark until the twoleaf stage, 32 cucumber seedlings were chosen and divided into four groups (eight plants per group) to impose the following treatments: I (control group), watered with $25 \mathrm{~mL}$ of autoclaved water; II (FA+PHBA treatment group), watered with $25 \mathrm{~mL}$ of solutions (containing $5.03 \mathrm{~g} \mathrm{~L}^{-1} \mathrm{FA}$ and $3.77 \mathrm{~g} \mathrm{~L}^{-1}$ PHBA) to make the mixture of FA and PHBA reach a concentration of $220 \mu \mathrm{g} \mathrm{g}^{-1}$ dry soil, which induced stress but did not cause plant wilting; III (CSY-P13 treatment group), watered with $25 \mathrm{~mL}$ of $5.84 \mathrm{log}$ cfu mL $\mathrm{mL}^{-1}$ CSY-P13 to reach a concentration of $7.24 \log \mathrm{cfu}^{\mathrm{plant}^{-1}}$; IV (CSYP13+FA+PHBA treatment group), watered with $25 \mathrm{~mL}$ of solutions (containing $5.84 \mathrm{log} \mathrm{cfu} \mathrm{mL}^{-1}$ CSY-P13, $5.03 \mathrm{~g} \mathrm{~L}^{-1}$ FA, and $3.77 \mathrm{~g} \mathrm{~L}^{-1}$ PHBA) to make CSY-P13 and the mixture of FA and PHBA reach the concentrations of $7.24 \log \mathrm{cfu}_{\text {plant }}{ }^{-1}$ and $220 \mu \mathrm{g} \mathrm{g}^{-1}$ dry soil, respectively. After that, the seedlings were maintained at $40 \%(\mathrm{w} / \mathrm{w})$ soil moisture with autoclaved $\mathrm{H}_{2} \mathrm{O}$ under conditions of $25^{\circ} \mathrm{C}$ and $12 \mathrm{~h}$ light $\left(600 \mu \mathrm{mol} \mathrm{m}{ }^{-2} \mathrm{~s}^{-1}\right) / 12 \mathrm{~h}$ dark. At 20 days after inoculation with CSY-P13, the fully expanded second leaves and rhizospheric soil of cucumber were collected. This experiment was repeated three times.

\section{Levels of Malondialdehyde, $\mathrm{O}_{2}^{\circ-}$, and $\mathrm{H}_{2} \mathrm{O}_{2}$ in Leaves}

Malondialdehyde (MDA) in cucumber leaves was extracted with $10 \%$ trichloroacetic acid, and its content was determined by thiobarbituric acid assay at 450, 532, and $600 \mathrm{~nm}$ (Xu P.L. et al., 2008). The formation rate of $\mathrm{O}_{2}^{\bullet-}$ was determined at $530 \mathrm{~nm}$ according to Elstner and Heupel (1976). The content of $\mathrm{H}_{2} \mathrm{O}_{2}$ was measured by monitoring a titanium peroxide complex at $415 \mathrm{~nm}$ (Mukherjee and Choudhuri, 1983).

\section{Activities of Antioxidant Enzymes in Leaves}

Leaf sample $(0.1 \mathrm{~g})$ was ground with liquid nitrogen and suspended in $1 \mathrm{~mL}$ of HEPES buffer $(25 \mathrm{mM}, \mathrm{pH} 7.8)$ containing $0.2 \mathrm{mM}$ EDTA and 2\% (w/v) PVP. After centrifugation at $4{ }^{\circ} \mathrm{C}$ and $12,000 \mathrm{~g}$ for $20 \mathrm{~min}$, the supernatant was the extract of SOD, CAT, GSH-Px, MDHAR, DHAR, and GR. To extract APX, $0.02 \mathrm{~g}$ of liquid nitrogen-ground cucumber leaves was suspended in $3 \mathrm{~mL}$ of HEPES buffer (25mM, pH 7.8), which contained $0.2 \mathrm{mM}$ EDTA, 2\% (w/v) PVP, and $2 \mathrm{mM}$ AsA. The activities of SOD, CAT, APX, and DHAR were assayed according to Zhang et al. (2012) as indicated above. The activities of MDHAR, GSH-Px, and GR were measured due to the oxidation of $\mathrm{NADH}$, decrease in $\mathrm{GSH}$, and oxidation of NADPH, respectively (Zhang et al., 2012). One unit of GSH-Px, MDHAR, and GR activity was defined as $1 \mu \mathrm{mol}$ of GSH decreased per minute, $1 \mathrm{nmol}$ of $\mathrm{NADH}$ oxidized in one minute, and $1 \mu \mathrm{mol}$ of NADPH oxidized per minute, respectively.

\section{Transcript Levels of Cu/Zn-SOD, $M n-S O D$, and CAT in Leaves}

To confirm the activities of SOD and CAT, transcript levels of $C u / Z n-S O D, M n-S O D$, and CAT in cucumber leaves were estimated using real-time quantitative RT-PCR. Total RNA was extracted from cucumber leaves with a TRIzol reagent (Invitrogen, Carlsbad, United States) and reverse-transcribed to cDNA using a Quantscript RT kit (Cwbio, China). PCR primers of $\mathrm{Cu} / \mathrm{Zn}$-SOD, $\mathrm{Mn}$-SOD, and CAT are listed in Supplementary Table S3. The PCR reaction mixture $(20 \mu \mathrm{L})$ contained $10 \mu \mathrm{L}$ of $2 \times$ ultra SYBR Mixture (with Rox; Cwbio, China), $2 \mu \mathrm{L}$ of template cDNA, and $0.8 \mu \mathrm{L}$ of $5 \mathrm{pM}$ forward and reverse primers. PCR parameters included an initial denaturation step at $95^{\circ} \mathrm{C}$ for $10 \mathrm{~min}$, followed by 40 amplification cycles of $15 \mathrm{~s}$ at $95^{\circ} \mathrm{C}$, and $1 \mathrm{~min}$ at $55^{\circ} \mathrm{C}$. PCR amplification was performed with the CFX96 $6^{\mathrm{TM}}$ real-time system (Bio-Rad, Hercules, United States) in triplicate. The transcript levels of $\mathrm{Cu} / \mathrm{Zn}-\mathrm{SOD}, \mathrm{Mn}-\mathrm{SOD}$, and CAT were normalized against the corresponding actin mRNA levels, and calculated with a $2^{-\Delta \Delta C t}$ comparative CT method.

\section{Antioxidant Contents in Leaves}

To verify the activities of DHAR, MDHAR, and GR, the level of AsA was determined at $525 \mathrm{~nm}$ in cucumber leaves according to Klein and Perry (1982), and the content of GSH was measured at $412 \mathrm{~nm}$ as described by Guri (1983).

\section{Activities of Soil Enzymes in Rhizospheric Soil}

The activities of CAT (Roberge, 1978), sucrase (Schinner and Von Mersi, 1990), urease (Douglas and Bremner, 1971), and alkaline phosphatase (Anupama et al., 2008) were assayed in cucumber rhizospheric soil due to the decompounding of $\mathrm{H}_{2} \mathrm{O}_{2}$, formation of reducing sugars from sucrose, production of $\mathrm{NH}_{3}$ $\mathrm{N}$ from urea, and formation of phosphate from disodium phenyl phosphate, respectively. One unit of CAT, sucrase, urease, and alkaline phosphatase activity was, respectively, defined as $1 \mathrm{~mL}$ of $\mathrm{KMnO}_{4}$ consumed in $20 \mathrm{~min}, 1 \mathrm{mg}$ of reducing sugars formed in $24 \mathrm{~h}, 1 \mathrm{mg}$ of $\mathrm{NH}_{3}-\mathrm{N}$ produced in $24 \mathrm{~h}$, and $1 \mathrm{mg}$ of $\mathrm{P}_{2} \mathrm{O}_{5}$ produced in $2 \mathrm{~h}$.

\section{DNA Extraction, High Throughput Sequencing, and Data Processing of Soil Microorganisms in Rhizospheric Soil}

Soil microorganism DNA was extracted from cucumber rhizosphere soil using an EZNA ${ }^{\circledR}$ Soil DNA Kit (Omega Bio-tek, Norcross, GA, United States). Then, high throughput sequencing and data processing for 16S rRNA genes were performed at Shanghai Personal Biotechnology Co., Ltd. according to the procedures of Tao et al. (2017). Raw sequences data for bacterial 16S rRNA genes were deposited in NCBI's Sequence Read Archive (SRA) with the accession number SRP128603. Relative abundance of an operational taxonomic unit (OTU) was given by the number of clone sequences in each OTU in relation to the total number of clones in each sample. 


\section{Statistical Analysis}

All data are presented as means \pm standard errors of three biological replicates. One-way analysis of variance (ANOVA) and the least significant difference (LSD) were performed to analyze differences among treatments using SPSS for Windows 22.0 software (IBM Corp., Armonk, NY, United States). P-Values less than 0.05 were considered significant.

\section{RESULTS}

\section{Identification of CSY-P13}

Phylogenetic analysis (Supplementary Figure S1) and sequence alignment of 16S rRNA gene sequences showed that CSY-P13 exhibited $100 \%$ identity with A. calcoaceticus. Also, CSY-P13 showed the physiological and biochemical characteristics of Acinetobacter (Supplementary Table S4). Thus, this isolate was identified as A. calcoaceticus CSY-P13.

\section{Properties of CSY-P13}

When CSY-P13 was inoculated for $6 \mathrm{~h}$, the percentages of degraded FA and PHBA decreased with increasing initial concentrations of the mixture of FA and PHBA (Supplementary Figure S2A). CSY-P13 degraded FA and PHBA completely in $0.1 \mathrm{~g} \mathrm{~L}^{-1}$ mixture of FA and PHBA. However, the strain decomposed $91.28 \% \mathrm{FA}$ and $87.26 \% \mathrm{PHBA}$ in $0.2 \mathrm{~g} \mathrm{~L}^{-1}$ mixture of FA and PHBA and resulted in the highest amounts of degraded FA and PHBA and the best cell growth. Therefore, $0.2 \mathrm{~g} \mathrm{~L}^{-1}$ was chosen as the optimum initial concentration of the mixture of FA and PHBA.

As $\mathrm{NH}_{4} \mathrm{Cl}$ in $\mathrm{M}-9$ medium was replaced by ammonium sulfate, sodium nitrate, and urea, the percentages of degraded FA or PHBA by CSY-P13 did not change significantly $(P>0.05)$ (Supplementary Figure S2B). Under condition of $\mathrm{NH}_{4} \mathrm{Cl}$, cell growth of CSY-P13 was the best $(P<0.05)$. So $\mathrm{NH}_{4} \mathrm{Cl}$ was the optimum nitrogen source.

The percentages of degraded FA and PHBA by CSY-P13 both increased from 18 to $40^{\circ} \mathrm{C}$ and reached a maximum at $40^{\circ} \mathrm{C}$ (Supplementary Figure S2C). From 40 to $45^{\circ} \mathrm{C}$, the percentages of degraded FA and PHBA decreased. Thus, $40^{\circ} \mathrm{C}$ was the optimum culture temperature of CSY-P13.

The percentages of degraded FA and PHBA increased from 130 to $180 \mathrm{rpm}$, and then decreased from 180 to $230 \mathrm{rpm}$ (Supplementary Figure S2D). Incubating CSY-P13 at a shaking speed of $180 \mathrm{rpm}$ for $2.5 \mathrm{~h}$, the percentages of degraded FA and PHBA reached a maximum. Therefore, $180 \mathrm{rpm}$ was chosen as the optimum shaking speed of CSY-P13.

At $\mathrm{pH} 7$, the percentage of degraded FA by CSY-P13 was higher $(P<0.01)$ than that at $\mathrm{pH} 6$ or 8 (Supplementary Figure S2E). After CSY-P13 inoculation, the percentage of degraded PHBA increased from $\mathrm{pH} 4$ to 6 and decreased from $\mathrm{pH} 6$ to 8 . At $\mathrm{pH}$ 6, the percentage of degraded PHBA by CSY-P13 had no change $(P>0.05)$ in comparison to that at $\mathrm{pH} 7$. Thus, $\mathrm{pH} 7$ was the optimum $\mathrm{pH}$ for FA and PHBA degradation by CSY-P13.

Incubating CSY-P13 in 10, 20, 30, 40, or $50 \mathrm{~g} \mathrm{~L}^{-1} \mathrm{KH}_{2} \mathrm{PO}_{4}$ for $2 \mathrm{~h}$, the percentages of degraded FA and PHBA and cell growth all increased from 10 to $30 \mathrm{~g} \mathrm{~L}^{-1} \mathrm{KH}_{2} \mathrm{PO}_{4}$ and then decreased from 30 to $50 \mathrm{~g} \mathrm{~L}^{-1} \mathrm{KH}_{2} \mathrm{PO}_{4}$ (Supplementary Figure S2F). With $30 \mathrm{~g} \mathrm{~L}^{-1} \mathrm{KH}_{2} \mathrm{PO}_{4}$, the percentages of degraded FA and PHBA by CSY-P13 reached maximum amounts. Therefore, $30 \mathrm{~g} \mathrm{~L}^{-1}$ was the optimum concentration of $\mathrm{KH}_{2} \mathrm{PO}_{4}$.

\section{Response Surface Optimization for FA and PHBA Degradation by CSY-P13}

A polynomial model was performed by using multiple regression analysis to show an interaction between variables in coded units and factors that influenced FA and PHBA degradation by CSY-P13. Coefficient estimates of the model and their ANOVA results (Supplementary Tables S5, S6) indicated that the $\mathrm{KH}_{2} \mathrm{PO}_{4}$ concentration, culture temperature, and $\mathrm{pH}$ were correlated with the percentages of degraded FA and PHBA by CSY-P13. As shown in a 3D response surface (Supplementary Figures S3, S4), optimal values of the variables were temperature $39.37^{\circ} \mathrm{C}, \mathrm{pH} 6.97$, and $\mathrm{KH}_{2} \mathrm{PO}_{4}$ concentration of $21.59 \mathrm{~g} \mathrm{~L}^{-1}$. Incubating CSY-P13 for $2 \mathrm{~h}$ under the predicted optimal conditions, the percentages of degraded FA and PHBA were 74.29 and $72.36 \%$, respectively, which were in agreement with the predicted degradation rates of FA (74.45\%) and PHBA (72.26\%) and indicated that the model was adequate for FA and PHBA degradation by CSY-P13.

\section{Bioconversion Products of the Mixture of FA and PHBA by CSY-P13 in Culture Solutions}

Incubating CSY-P13 for $2 \mathrm{~h}$ under conditions optimized by the response surface methodology, bioconversion products of the mixture of FA and PHBA included 4-vinyl guaiacol (4VG), protocatechuic acid (PA), vanillin, and vanillic acid (Figure 1A). Among these, the metabolites of FA contained $4 \mathrm{VG}$ and small quantities of PA, vanillin, and vanillic acid (Figures 1B,C); and only PA was detected during PHBA degradation (Figures 1D,E). During the degradation of the mixture of FA and PHBA by CSYP13, concentrations of $4 \mathrm{VG}$, vanillin, and vanillic acid increased from 0 to $4 \mathrm{~h}$, and they reached a maximum at $4 \mathrm{~h}$ and then decreased (Figure 1A). Meanwhile, PA reached a maximum yield at $5 \mathrm{~h}$.

\section{Effects of the Mixture of FA and PHBA on Antioxidant Enzyme Activity in CSY-P13}

Under conditions optimized by the response surface methodology, the activities of SOD (Figure 2A), CAT (Figure 2B), APX (Figure 2C), and DHAR (Figure 2D) in CSY-P13 were increased $(P<0.05)$ by the treatment of $\mathrm{FA}+\mathrm{PHBA}$ or FA alone or PHBA alone compared to the glucose treatment.

\section{Degradation of the Mixture of FA and PHBA by CSY-P13 in Soil}

Compared to control, the concentrations of FA (Figure 3A) and PHBA (Figure 3B) remaining in soil were decreased by $83.66 \%$ $(P<0.001)$ and $63.02 \%(P<0.001)$, respectively, in the CSY-P13 treatment. In the CSY-P13+FA+PHBA treatment in comparison to the FA+PHBA treatment, the concentrations of FA and PHBA 

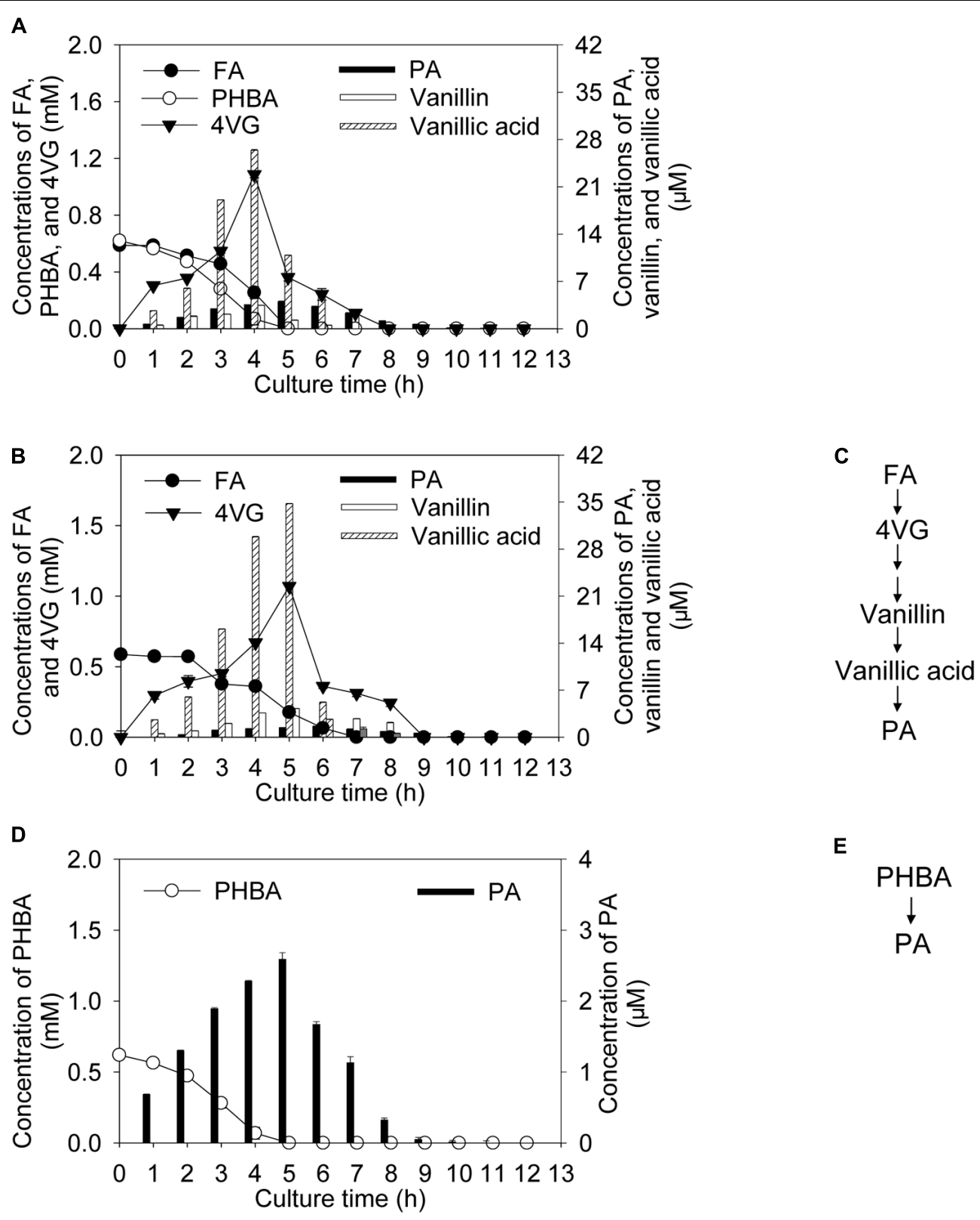

E

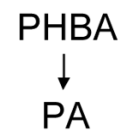

FIGURE 1 | Bioconversion products from the mixture of FA and PHBA (A), FA (B), and PHBA (D), and proposed pathway of FA (C) and PHBA (E) metabolism by CSY-P13. Bars represent standard errors of three biological replicates.

remaining were decreased by $95.48 \%(P<0.001)$ and $97.93 \%$ $(P<0.001)$, respectively.

\section{Effects of CSY-P13 and the Mixture of FA and PHBA on Plant Height}

Compared to control, plant height of cucumber was increased by $12.21 \%(P<0.05)$ in the CSY-P13 treatment and decreased by $8.55 \%(P<0.05)$ in the FA+PHBA treatment (Figure $4 \mathrm{~A})$. In the CSY-P13+FA+PHBA treatment in comparison to the FA+PHBA treatment, the plant height was increased by $37.02 \%$ $(P<0.001)$.

\section{Effects of CSY-P13 and the Mixture of FA and PHBA on MDA, $\mathrm{O}_{2}^{\circ-}$, and $\mathrm{H}_{2} \mathrm{O}_{2}$} Levels in Leaves

In comparison to control, the levels of MDA (Figure $4 \mathbf{B}$ ), $\mathrm{O}_{2}^{\bullet-}$ (Figure 4C), and $\mathrm{H}_{2} \mathrm{O}_{2}$ (Figure 4D) in cucumber leaves were decreased by $9.49 \%(P<0.01), 12.15 \%(P<0.01)$, and $13.41 \%(P<0.01)$, respectively, in the CSY-P13 treatment and increased by $38.52 \%(P<0.01), 19.88 \%(P<0.001)$, and $8.53 \%$ $(P<0.05)$, respectively, in the FA+PHBA treatment. Compared the CSY-P13+FA+PHBA treatment to the FA+PHBA treatment, the levels of $\mathrm{MDA}, \mathrm{O}_{2}^{\bullet-}$, and $\mathrm{H}_{2} \mathrm{O}_{2}$ in cucumber leaves were 

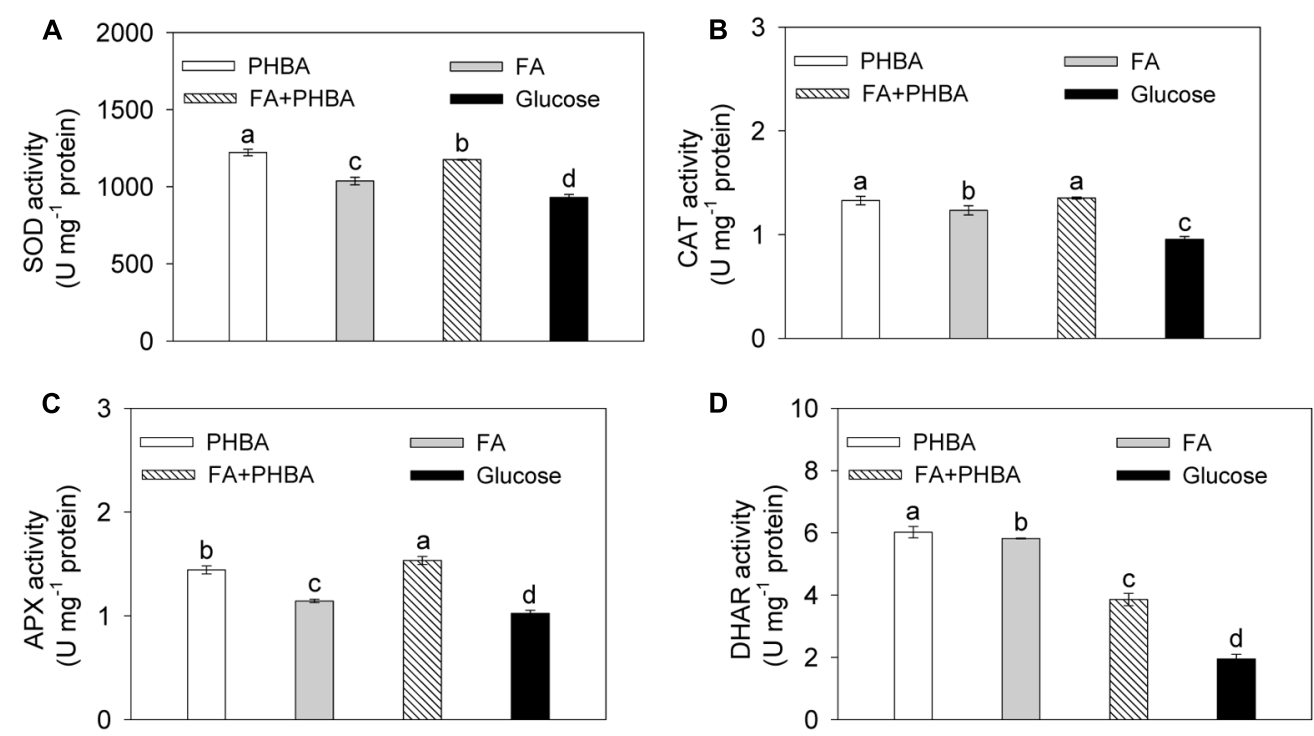

FIGURE 2 | Activities of SOD (A), CAT (B), APX (C), and DHAR (D) in CSY-P13. PHBA, cultured in PHBA; FA, cultured in FA; FA+PHBA, cultured in the mixture of FA and PHBA; glucose, cultured in glucose. Bars represent standard errors of three biological replicates. Values with the different letters are significantly different at $P<0.05$ by LSD test using SPSS for Windows 22.0 software (IBM Corp., Armonk, NY, United States).
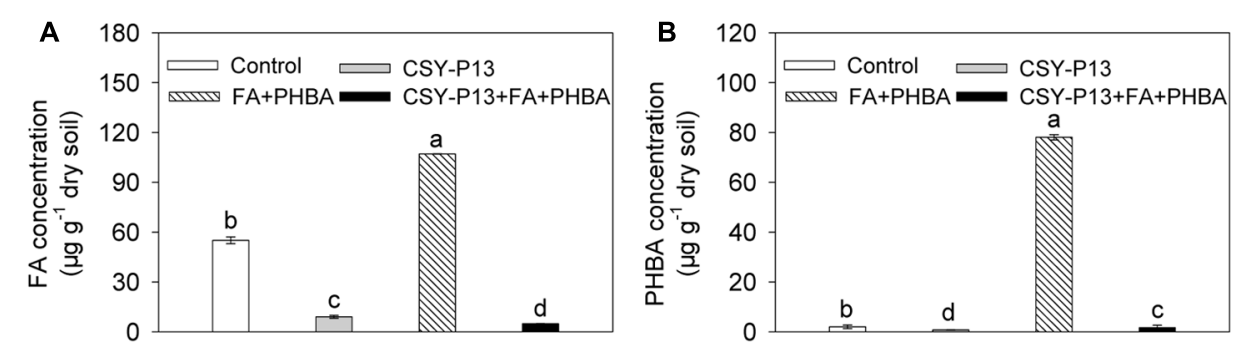

FIGURE 3 | FA (A) and PHBA (B) degradation by CSY-P13 in cucumber-planted soil. Control, supplemented with water; FA+PHBA, supplemented with the mixture of FA and PHBA; CSY-P13, supplemented with CSY-P13; CSY-P13+FA+PHBA, supplemented with CSY-P13 and the mixture of FA and PHBA. Bars represent standard errors of three biological replicates. Values with the different letters are significantly different at $P<0.05$ by LSD test using SPSS for Windows 22.0 software (IBM Corp., Armonk, NY, United States).

decreased by $36.65 \%(P<0.001), 33.18 \%(P<0.001)$, and $26.96 \%$ $(P<0.01)$, respectively.

\section{Effects of CSY-P13 and the Mixture of FA and PHBA on Antioxidant Enzyme Activities in Leaves}

Compared to control, the activities of SOD (Figure 5A), APX (Figure 5B), CAT (Figure 5C), DHAR (Figure 5D), MDHAR (Figure 5E), and GR (Figure 5F) in cucumber leaves were, respectively, increased by $31.7 \%(P<0.001), 22.86 \%(P<0.001)$, 39.49\% $(P<0.001), 22.57 \%(P<0.001), 6.33 \%(P<0.05)$, and $14.51 \%(P<0.001)$ in the CSY-P13 treatment, and, respectively, decreased by $20.74 \%(P<0.001), 12.76 \%(P<0.01), 30.46 \%$ $(P<0.001), 16.26 \%(P<0.001), 18.97 \%(P<0.001)$, and $33.56 \%$ $(P<0.001)$ in the FA+PHBA treatment. Meanwhile, the activity of GSH-Px (Figure 5G) in cucumber leaves did not change $(P>0.05)$ when compared the CSY-P13 treatment with control and decreased by $83.27 \%(P<0.001)$ in the FA+PHBA treatment in comparison to control. Compared the CSY-P13+FA+PHBA treatment to the FA+PHBA treatment, the activities of SOD, APX, CAT, GSH-Px, DHAR, MDHAR, and GR in cucumber leaves were enhanced by $51.26 \%(P<0.001), 68.17 \%(P<0.001)$, 74.47\% $(P<0.001), 84.47 \%(P<0.001), 65.32 \%(P<0.001)$, $32.58 \%(P<0.001)$, and $46.1 \%(P<0.001)$, respectively.

\section{Effects of CSY-P13 and the Mixture of FA and PHBA on Transcript Levels of Cu/Zn-SOD, Mn-SOD, and CAT in Leaves}

In comparison to control, the transcript levels of $\mathrm{Cu} / \mathrm{Zn}-\mathrm{SOD}$ (Figure 6A), $M n-S O D$ (Figure 6B), and CAT (Figure 6C) in cucumber leaves were, respectively, increased by $20.67 \%$ $(P<0.001)$, 39.9\% $(P<0.001)$, and 51.62\% $(P<0.001)$ in the CSY-P13 treatment, and, respectively, decreased by $15.27 \%$ $(P<0.01), 18.64 \%(P<0.001)$, and $18.72 \%(P<0.001)$ in the 

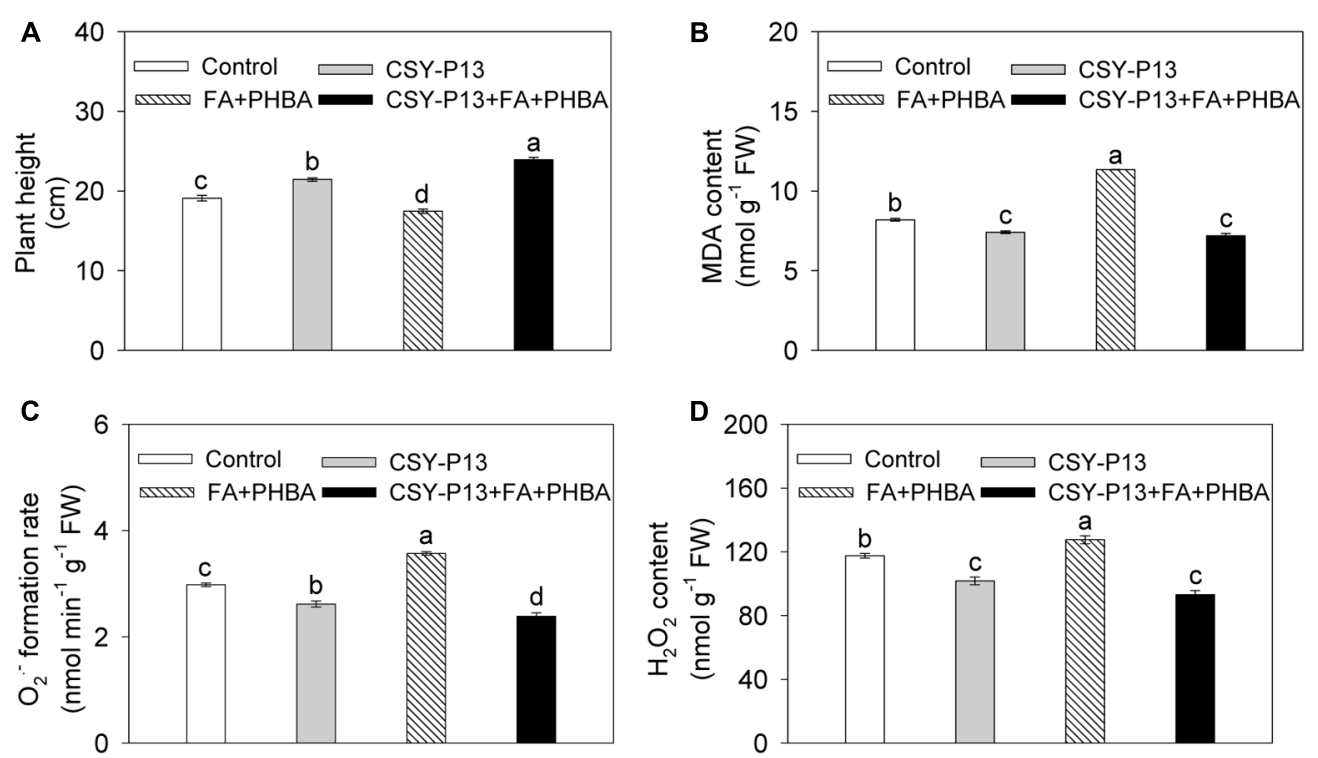

FIGURE 4 | Effects of CSY-P13 and the mixture of FA and PHBA on plant height (A), and levels of MDA (B), $\mathrm{O}_{2}^{\bullet-}$ (C), and $\mathrm{H}_{2} \mathrm{O}_{2}$ (D) in cucumber leaves. Bars represent standard errors of three biological replicates. Values with the different letters are significantly different at $P<0.05$ by LSD test using SPSS for Windows 22.0 software (IBM Corp., Armonk, NY, United States).

$\mathrm{FA}+\mathrm{PHBA}$ treatment. In the CSY-P13+FA+PHBA treatment in comparison to the FA+PHBA treatment, the transcript levels of $C u / Z n-S O D, M n-S O D$, and $C A T$ in cucumber leaves were increased by $53.13 \%(P<0.001), 107.45 \%(P<0.001)$, and $147.1 \%(P<0.001)$, respectively.

\section{Effects of CSY-P13 and the Mixture of FA and PHBA on AsA and GSH Contents in Leaves}

Compared to control, the contents of AsA (Figure 6D) and GSH (Figure 6E) in cucumber leaves were increased by $13.79 \%$ $(P<0.01)$ and $6.88 \%(P<0.05)$, respectively, in the CSY-P13 treatment and, respectively, decreased by $11.27 \%(P<0.05)$ and $16.96 \%(P<0.05)$ in the $\mathrm{FA}+\mathrm{PHBA}$ treatment. In comparison to the FA+PHBA treatment, the contents of AsA and GSH were increased by $41.92 \%(P<0.001)$ and $45.31 \%(P<0.001)$, respectively, in cucumber leaves of the CSY-P13+FA+PHBA treatment.

\section{Effects of CSY-P13 and the Mixture of FA and PHBA on Soil Enzyme Activities}

In comparison to control, the activities of phosphatase (Figure 7A), CAT (Figure 7B), urease (Figure 7C), and sucrase (Figure 7D) in rhizospheric soil were, respectively, increased by $5.23 \%(P<0.05), 4.45 \%(P<0.05), \quad 5.07 \%$ $(P<0.05)$, and $2.26 \%(P<0.05)$ in the CSY-P13 treatment and, respectively, decreased by $20.30 \%(P<0.001), 4.58 \%(P<0.05)$, $8.14 \%(P<0.05)$, and $13.13 \%(P<0.01)$ in the PHBA+FA treatment. Compared the CSY-P13+FA+PHBA treatment with the FA+PHBA treatment, the activities of phosphatase, CAT, urease, and sucrase in rhizospheric soil were increased by $95.35 \%$
$(P<0.001), 15.37 \%(P<0.05), 37.38 \%(P<0.001)$, and $16.31 \%$ $(P<0.001)$, respectively.

\section{Effects of CSY-P13 and the Mixture of FA and PHBA on Bacterial Richness and Diversity in Rhizospheric Soil}

When low-quality sequences with an average quality score less than 20, length shorter than $150 \mathrm{bp}$, any mismatches to the primers, or a homopolymer longer than eight bases were removed, 40,498, 43,252, 40,082, and 40,660 high-quality sequences were obtained from the treatments of control, CSY$\mathrm{P} 13, \mathrm{FA}+\mathrm{PHBA}$, and CSY-P13+FA+PHBA, respectively. All rarefaction curves tended to reach saturation with the increase of sequence numbers (Supplementary Figure S5), suggesting the sufficient sequencing depth was achieved in each treatment.

Bacterial richness in rhizospheric soil was evaluated using the Chaol (Figure 8A) and ACE (Figure 8B) richness estimators. We examined the effect of CSY-P13, finding that both Chaol and ACE richness estimators were increased significantly $(P<0.05)$ in the CSY-P13 treatment in comparison to the control or in the CSY-P13+FA+PHBA treatment when compared to the FA+PHBA treatment. So CSY-P13 increased bacterial richness in rhizospheric soil. We next tested the effect of the mixture of FA and PHBA and found that the Chaol and ACE richness estimators both did not change significantly $(P>0.05)$ between the FA+PHBA treatment and control. This indicated that the mixture of FA and PHBA did not affect bacterial richness in rhizospheric soil.

To investigate bacterial diversity in rhizospheric soil, the Simpson (Figure 8C) and Shannon (Figure 8D) indices were analyzed. In the CSY-P13 treatment in comparison to the control 

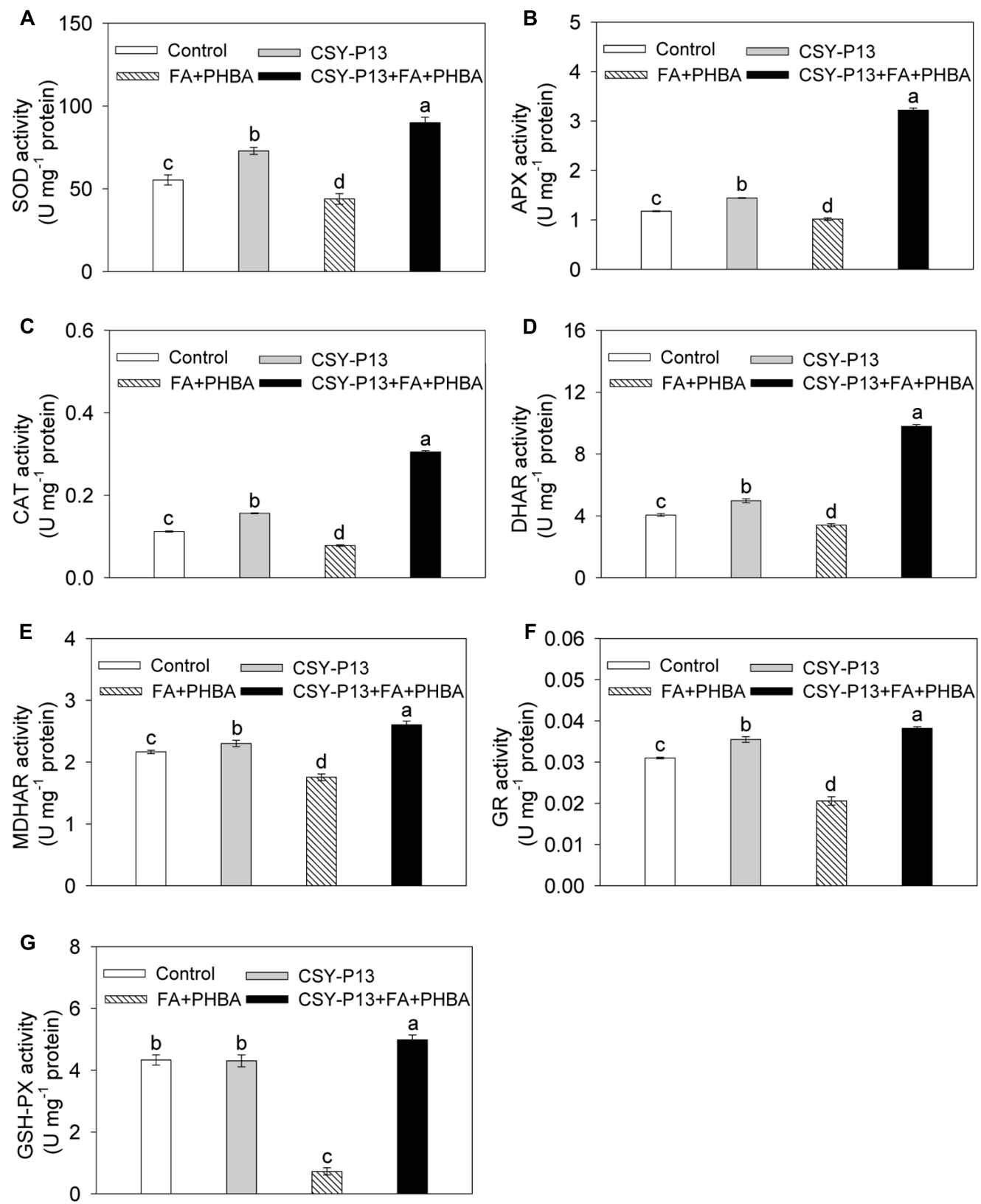

FIGURE 5 | Effects of CSY-P13 and the mixture of FA and PHBA on SOD (A), APX (B), CAT (C), DHAR (D), MDHAR (E), GR (F), and GSH-Px (G) activities in cucumber leaves. Bars represent standard errors of three biological replicates. Values with the different letters are significantly different at $P<0.05$ by LSD test using SPSS for Windows 22.0 software (IBM Corp., Armonk, NY, United States).

or in the CSY-P13+FA+PHBA treatment compared to the FA+PHBA treatment, the Simpson and Shannon indices were both increased significantly $(P<0.05)$. Compared the FA+PHBA treatment with control, the Simpson and Shannon indices did not differ $(P>0.05)$. Therefore, CSY-P13 increased bacterial diversity in rhizospheric soil, and the mixture of FA and PHBA did not affect it.

Variations of OTUs were observed among treatments. The number of OTUs in the control, CSY-P13, FA+PHBA, and CSYP13+FA+PHBA treatments was 3726, 3866, 3620, and 3845, respectively. Venn diagrams showed that bacterial communities of four treatments shared many OTUs (Supplementary Figure S6). There were 2219 shared OTUs detected in the rhizospheric soil of all four treatments. Considerable overlap was observed in the CSY-P13-treated rhizospheric soils, with the CSY-P13 treatment and the CSY-P13+FA+PHBA treatment having 3244 shared OTUs. Similarly, the rhizospheric soils treated with the mixture of FA and PHBA had considerable overlap, with the CSY-P13+FA+PHBA treatment and the FA+PHBA treatment having 3105 shared OTUs. 

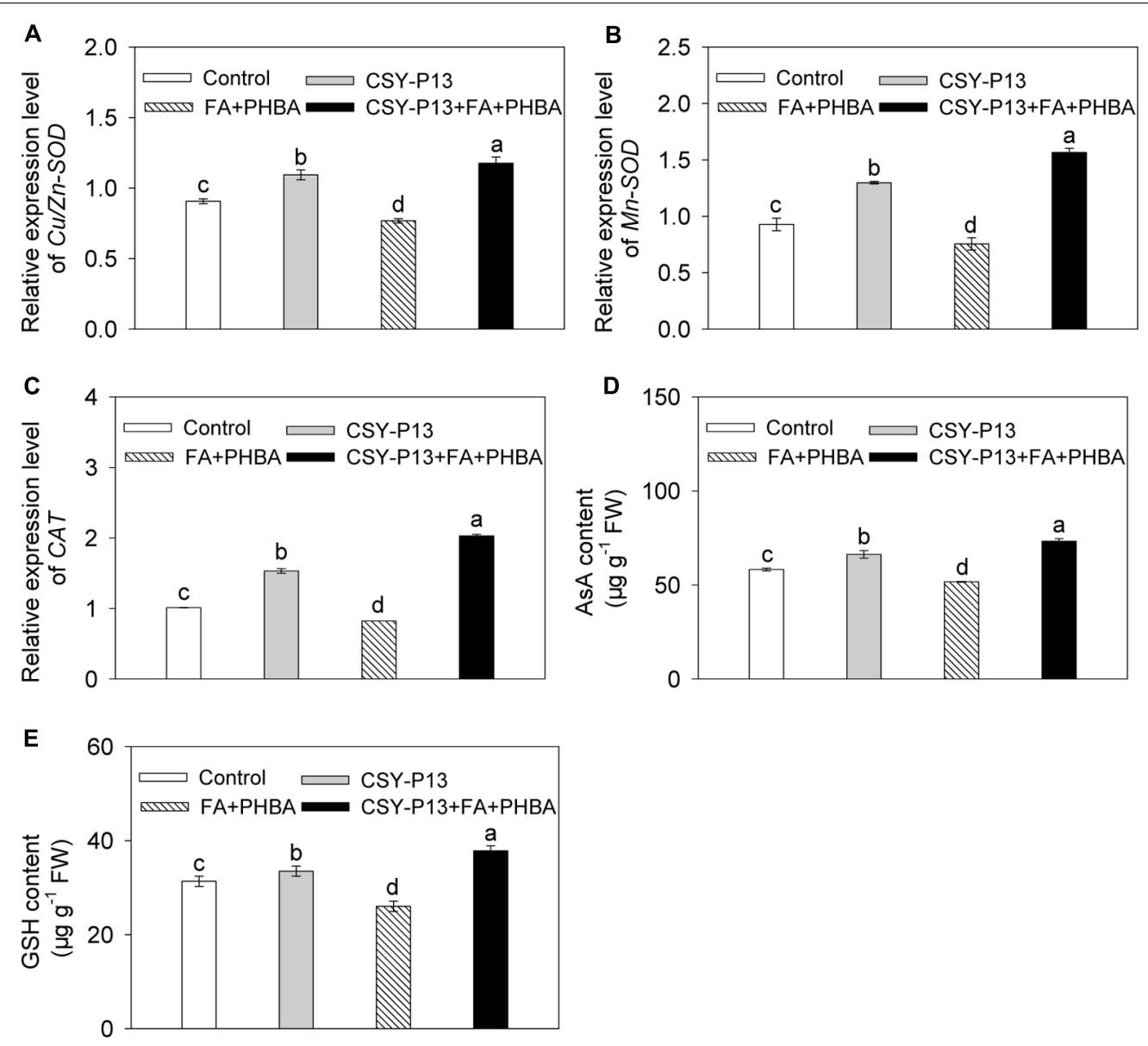

FIGURE 6 | Effects of CSY-P13 and the mixture of FA and PHBA on transcript levels of Cu/Zn-SOD (A), Mn-SOD (B), and CAT (C), and contents of AsA (D) and GSH (E) in cucumber leaves. Bars represent standard errors of three biological replicates. Values with the different letters are significantly different at $P<0.05$ by LSD test using SPSS for Windows 22.0 software (IBM Corp., Armonk, NY, United States).

\section{Effects of CSY-P13 and the Mixture of FA and PHBA on Bacterial Community Composition and Structure in Rhizospheric Soil}

In rhizospheric soil of all four treatments, there were 27 phyla (Supplementary Figure S7A), 63 classes (Supplementary Figure S7B), 103 orders (Supplementary Figure S8A), 184 families (Supplementary Figure S8B), and 389 genera (Supplementary Figure S9). The dominant phyla were Firmicutes, Proteobacteria, Actinobacteria, and Bacteroidetes, respectively, representing $50.17,29.76,11.44$, and $5.00 \%$ in the rhizospheric soil of control; $51.34,33.07,7.84$, and $4.57 \%$ in the CSY-P13 treatment; 47.98 , $39.84,4.21$, and $5.15 \%$ in the FA+PHBA treatment; and 41.40, $43.25,4.85$, and $6.55 \%$ in the CSY-P13+FA+PHBA treatment. In Proteobacteria phylum, 272 genera were detected. Among these, Acinetobacter was the second dominant genus, representing 1.48, $2.15,4.05$, and $3.94 \%$ in the control, CSY-P13, FA+PHBA, and CSY-P13+FA+PHBA treatments, respectively.

One kind of OTU was identified as A. calcoaceticus by using $16 \mathrm{~S}$ rRNA gene sequences, and it was the first dominant species in Acinetobacter. Compared to control, the relative abundance of $A$. calcoaceticus was significantly $(P<0.01)$ increased in the CSY-P13 over FA+PHBA treatment (Figure 9). In the CSY$\mathrm{P} 13+\mathrm{FA}+\mathrm{PHBA}$ treatment in comparison to the FA+PHBA treatment, the abundance of $A$. calcoaceticus was significantly $(P<0.001)$ increased as well.

Clustering analysis was performed according to bacterial composition at the genus level, with bacteria from the same branch having higher similarity (Figure 10). Bacteria from the FA+PHBA and the CSY-P13+FA+PHBA treatments clustered together and were different from those from the CSY-P13 treatment and control, indicating that the mixture of FA and PHBA had a significant impact on bacterial community structure in rhizospheric soil.

A principal component analysis based on genera abundance showed distinct differences in bacterial composition of rhizospheric soil (Supplementary Figure S10). The bacterial community of the FA+PHBA treatment separated from those of control or the CSY-P13+FA+PHBA treatment by the second component (PC2, accounted for $14.1 \%$ of the variance). 

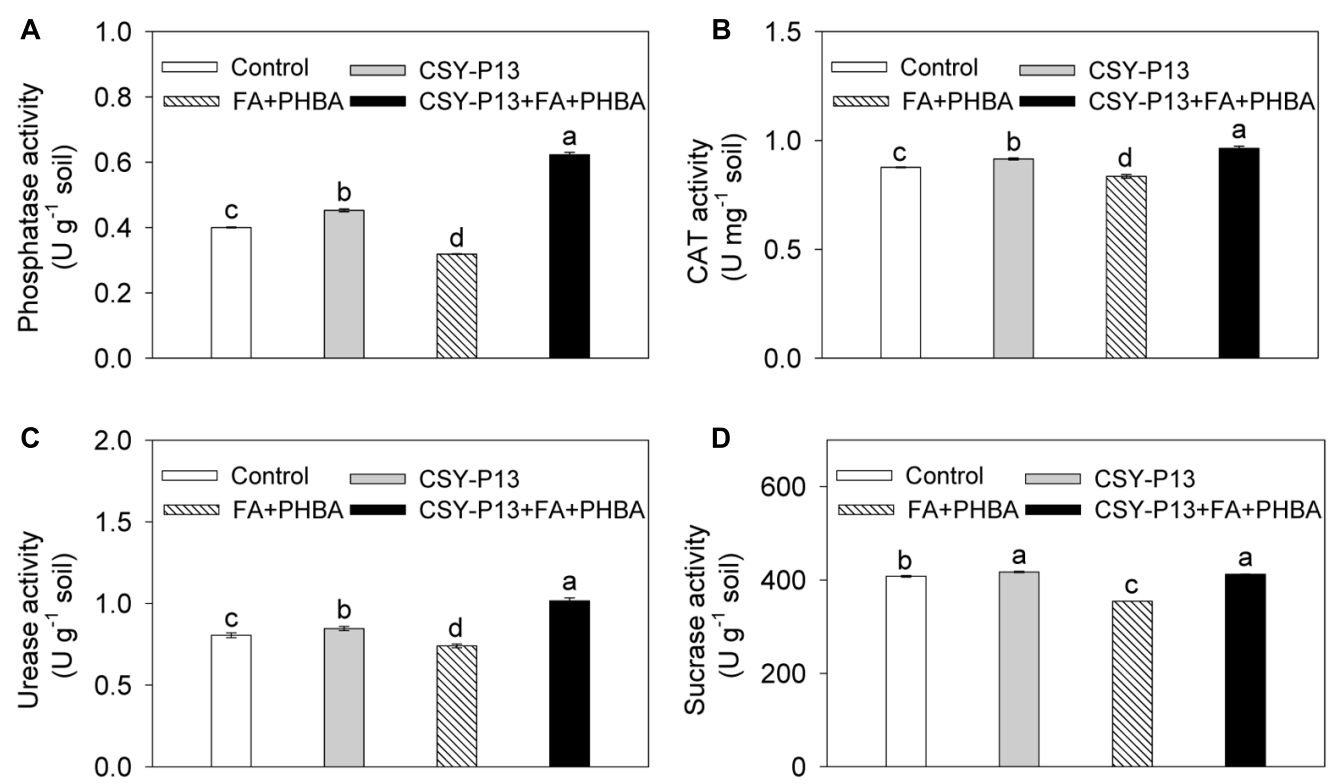

FIGURE 7 | Effects of CSY-P13 and the mixture of FA and PHBA on phosphatase (A), CAT (B), urease (C), and sucrase (D) activities in cucumber rhizospheric soil. Bars represent standard errors of three biological replicates. Values with the different letters are significantly different at $P<0.05$ by LSD test using SPSS for Windows 22.0 software (IBM Corp., Armonk, NY, United States).
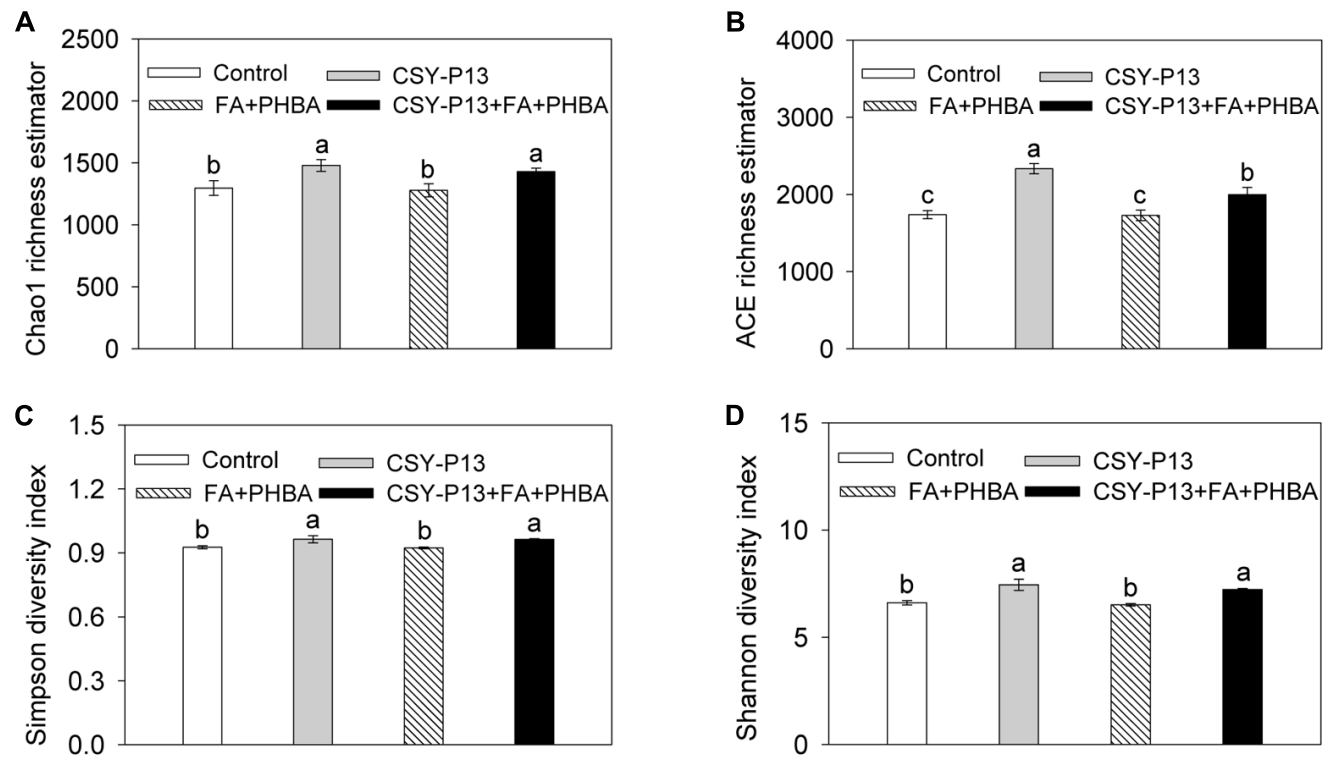

FIGURE 8 | Effects of CSY-P13 and the mixture of FA and PHBA on bacterial richness and diversity in cucumber rhizospheric soil by the Chao1 (A) and ACE (B) richness estimators and the Simpson (C) and Shannon (D) indices. Bars represent standard errors of three biological replicates. Values with the different letters are significantly different at $P<0.05$ by LSD test using SPSS for Windows 22.0 software (IBM Corp., Armonk, NY, United States).

\section{DISCUSSION}

Plant growth and MDA content are indicators of stress damage in plants (Huang et al., 2015). The mixture of FA and PHBA in this study not only decreased cucumber plant height but also increased the content of MDA in cucumber leaves, whereas CSYP13 increased the plant height and decreased the content of MDA under conditions of FA and PHBA. There results indicated that the mixture of FA and PHBA causes stress in cucumber plants and applying CSY-P13 into cucumber-planted soil can mitigate the stress of FA and PHBA.

Acinetobacter calcoaceticus CSY-P13 from the cucumber rhizosphere in this study effectively degraded the mixture of FA and PHBA not only in culture solution but also in 


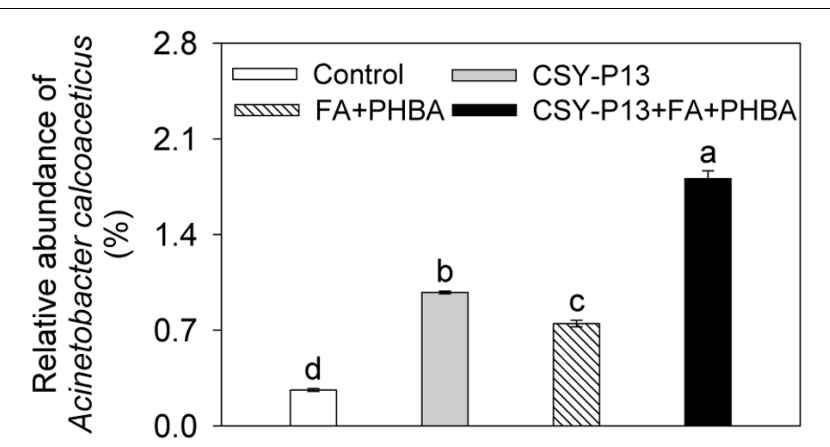

FIGURE 9 | Effects of CSY-P13 and the mixture of FA and PHBA on relative abundance of one OTU, which is identified as Acinetobacter calcoaceticus by using sequence alignment of 16S rRNA gene sequences. Bars represent standard errors of three biological replicates. Values with the different letters are significantly different at $P<0.05$ by LSD test using SPSS for Windows 22.0 software (IBM Corp., Armonk, NY, United States).

cucumber-planted soil. This can be supported by a report that A. calcoaceticus DSM586 have the capability to degrade benzoic acid, PHBA, and vanillic acid in culture solution (Delneri et al., 1995). We propose that CSY-P13 mitigates the stress of FA and PHBA in cucumber by degrading FA and PHBA in soil.

The metabolites $4 \mathrm{VG}$, vanillin, vanillic acid, and PA were detected during FA degradation by CSY-P13 in this study. Karmakar et al. (2000) observed the same metabolites from FA degradation by Bacillus coagulans BK07. As shown in Figure 1C, we propose a pathway of FA metabolism by CSY-P13 in reference to Karmakar et al. (2000). During PHBA degradation by CSYP13, PA was a metabolite in the current study. Similarly, PHBA is converted to PA by Pseudomonas putida CSY-P1 (Chen et al., 2015). The concentrations of these metabolites (4VG, vanillin, vanillic acid, and PA) all increased first and then decreased during degradation of the mixture of FA and PHBA by CSY$\mathrm{P} 13$, indicating that the strain in this study can decompose the metabolites of FA and PHBA and do not result in stresses of these metabolites to plants. Similarly, Acinetobacter strains have the ability to degrade vanillin (Gawai et al., 2005), vanillic acid (Delneri et al., 1995), and PA (Sparnins et al., 1974).

MDA is a product of membrane lipid peroxidation, which can be induced by the overproduction of $\mathrm{H}_{2} \mathrm{O}_{2}$ and $\mathrm{O}_{2}^{\bullet-}$ in plants under environmental stresses (Smirnoff, 1993). Therefore, the stress caused by the mixture of FA and PHBA in the current study resulted in the enhanced levels of $\mathrm{H}_{2} \mathrm{O}_{2}$ and $\mathrm{O}_{2}^{\bullet-}$ in leaves, consistent with the increase in MDA content. FA-degrading Bacillus methylotrophicus CSY-F1 (Zhang et al., 2015) decreases the levels of $\mathrm{H}_{2} \mathrm{O}_{2}, \mathrm{O}_{2}^{\bullet-}$, and MDA in cucumber leaves under FA conditions. In this study, inoculation with CSY-P13 into cucumber-planted soil also resulted in the decreased levels of $\mathrm{H}_{2} \mathrm{O}_{2}, \mathrm{O}_{2}^{\bullet-}$, and MDA in leaves under the mixture of FA and PHBA. These results were consistent with the increased plant height in the CSY-P13+FA+PHBA treatment in comparison to the FA+PHBA treatment, indicating that CSY-P13 mitigates the stress of the two phenolic compounds by decreasing ROS levels in cucumber.
The ROS levels can be regulated by antioxidant enzymes in plants (Zhang et al., 2012), so we determined the activities of these enzymes in cucumber seedlings. As a response to the mixture of FA and PHBA in this study, the activities of SOD, CAT, APX, GSH-Px, DHAR, MDHAR, and GR were decreased in leaves. Similarly, the activity of SOD is inhibited in maize seedlings under antimony stress (Pan et al., 2011). On the other hand, inoculation by Serratia marcescens and Glomus intraradices elevates antioxidant enzyme activities in oat plantlets grown in petroleum-contaminated soil (Dong et al., 2014). When CSY-P13 has been added to cucumber-planted soil containing the mixture of FA and PHBA, the activities of SOD, CAT, APX, GSH-Px, DHAR, MDHAR, and GR were higher in leaves than those in the FA+PHBA treatment, which were consistent with the increased transcript levels of $\mathrm{Cu} / \mathrm{Zn}$-SOD, $\mathrm{Mn}$-SOD, and CAT, in agreement with the enhanced levels of AsA and GSH, and in accord with the decreased levels of $\mathrm{H}_{2} \mathrm{O}_{2}, \mathrm{O}_{2}^{\bullet-}$, and MDA. These indicated that CSY-P13 may activate antioxidant enzymes, which play a role in decreasing ROS levels. As a result, membrane lipid peroxidation and the stress from FA and PHBA will be alleviated in cucumber.

Using high throughput sequencing, the absolute abundance of A. calcoaceticus in cucumber rhizosphere was higher in the CSY-P13 treatment in comparison to the control or in the CSY-P13+FA+PHBA treatment compared to the FA+PHBA treatment, suggesting that CSY-P13 colonizes roots. However, after CSY-P13 inoculation, we not only observed $A$. calcoaceticus but also obtained other bacteria in the rhizosphere. In the CSY-P13-uninoculated treatments that were regarded as the control experiments, these bacteria were observed as well. The reason may be that the soil in this study was only autoclaved and then air-dried before culturing cucumber seedlings, and bacteria besides CSY-P13 might grow. This makes it possible to investigate the effects of CSY-P13 on soil bacterial community. The dominant phyla observed in cucumber rhizosphere of the current study were Firmicutes, Proteobacteria, Actinobacteria, and Bacteroidetes. Hollister et al. (2010) also found that these four phyla were the most common dominant microflora in soil. CSYP13 increased bacterial richness and diversity in rhizospheric soil according to the Chaol and ACE richness estimators and the Simpson and Shannon indices, whereas the results of clustering analysis showed that the mixture of FA and PHBA had an impact on bacterial community structure as well. Similarly, applying biofertilizer containing Bacillus amyloliquefaciens to a banana orchard increases diversity of bacteria in soil (Shen et al., 2015), and soil phenolics change soil microbial communities (Zhou et al., 2012).

In order to further analyze the effects of CSY-P13 and the mixture of FA and PHBA on rhizospheric microorganisms, we determined the activities of soil enzymes, which reflect the composition of soil microbial community (Kim et al., 2012). Firmicutes have an important role on soil $C$ and $\mathrm{N}$ cycling (Ferreira et al., 2015), and Proteobacteria and Bacteroidetes are important contributors to $\mathrm{N}$ cycling in soil (van Spanning et al., 2005) and induce phosphatase when inorganic phosphate is insufficient (Sebastian and Ammerman, 2009), while Actinobacteria play a critical role in soil C mineralization (Tardy et al., 2015). Therefore, the activities of urease, phosphatase, and 


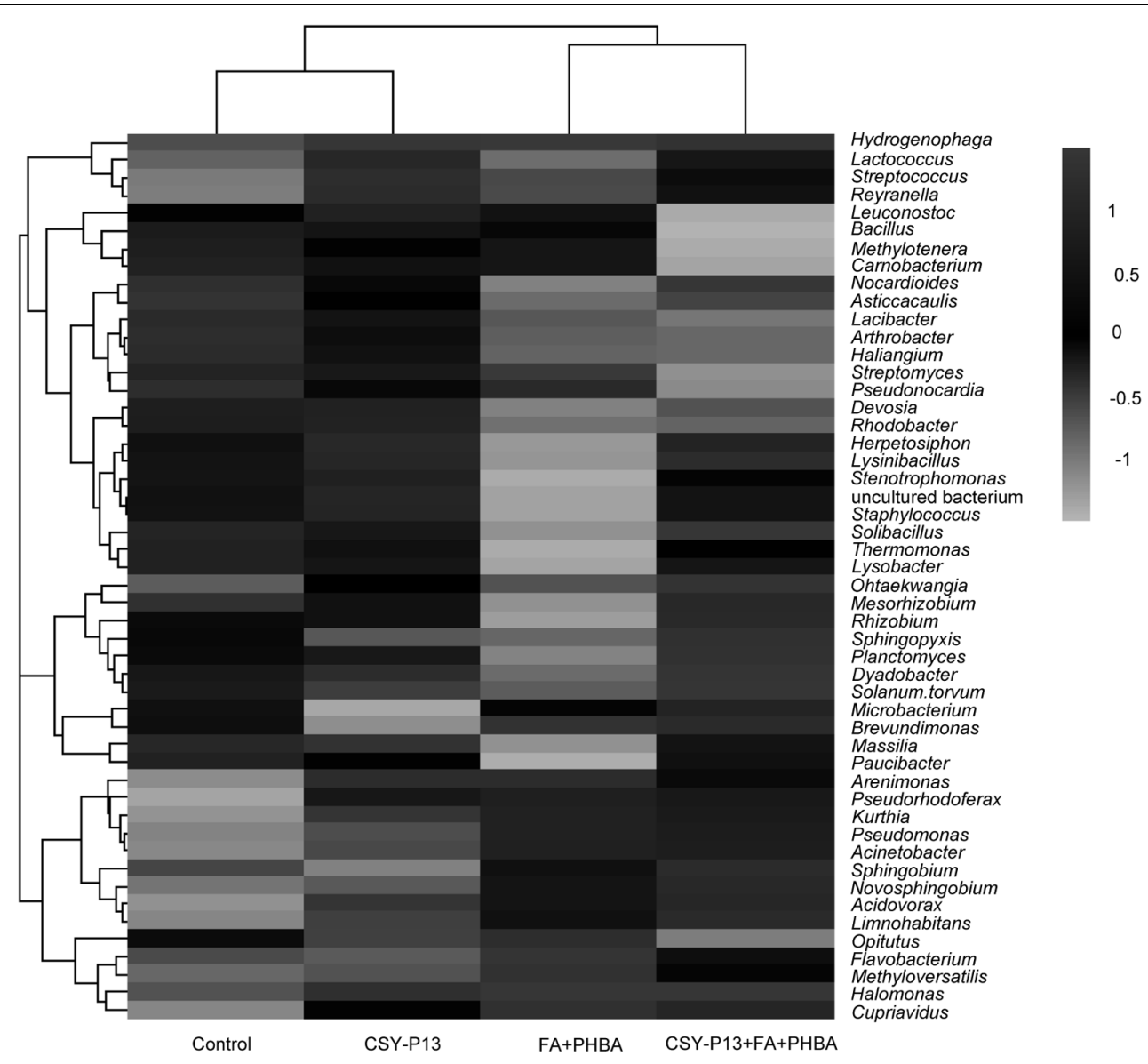

FIGURE 10 | Heatmap showing the relative abundance of the top 50 abundant bacterial genera in rhizospheric soil. Phylogenetic trees are performed using the neighbor-joining method. Shading zones represent the relative abundance of different treatments within each genus. For a certain genus, when the shading intensity of one treatment is between 0 and 1 , the abundance value of the genus in this treatment is higher than the mean abundance value of the genus in four treatments; when the shading intensity of one treatment is between 0 and -1 , the abundance value of the genus in this treatment is lower than the mean abundance value of the genus in all treatments.

sucrase in cucumber rhizosphere soil were determined in this study. As an indicator of aerobic microbial activity (García and Hernández, 1997), CAT activity in soil was also determined. The activities of urease, phosphatase, sucrase, and CAT were reduced by the mixture of FA and PHBA. Similarly, when exogenous PHBA was applied to cucumber-planted soil, activities of these four soil enzymes were decreased (Chen et al., 2015). On the other hand, inoculation with S. marcescens and G. intraradices to the petroleum-rich soil causes an increased activity of urease (Dong et al., 2014). In the present experiment, after CSYP13 was inoculated to cucumber-planted soil containing the mixture of FA and PHBA, the activities of phosphatase, urease, sucrase, and CAT in rhizosphere soil were increased, consistent with decreased level of MDA and the increased level of plant height in cucumber. These results suggested that CSY-P13 affects the bacterial community in rhizospheric soil and induces soil enzymes, thus mitigating the stress of FA and PHBA in cucumber.

CAT in a phenol-degrading strain of A. calcoaceticus plays a role in short-term adaptation of this strain to stress induced by phenol (Benndorf et al., 2004). In CSY-P13 exposed to FA and PHBA, the activities of SOD, CAT, APX, and DHAR were elevated. We proposed that the induction of antioxidant enzymes in FA- and PHBA-degrading CSY-P13 contributes to tolerance of this strain to FA and PHBA stress.

\section{CONCLUSION}

CSY-P13 from cucumber rhizosphere was identified as A. calcoaceticus CSY-P13. This strain effectively degraded the mixture of FA and PHBA, giving rise to $4 \mathrm{VG}$, vanillin, vanillic acid, and PA. The optimum conditions for FA and PHBA degradation by CSY-P13 were $39.37^{\circ} \mathrm{C}$, $\mathrm{pH}$ 6.97, and $\mathrm{KH}_{2} \mathrm{PO}_{4}$ concentration of $21.59 \mathrm{~g} \mathrm{~L}^{-1}$. During FA and PHBA degradation, the activities of SOD, CAT, APX, and DHAR were increased in CSY-P13. Inoculation with CSY-P13 increased plant height and decreased the levels of $\mathrm{MDA}_{2} \mathrm{O}_{2}^{\bullet-}$, and $\mathrm{H}_{2} \mathrm{O}_{2}$ in cucumber grown in soil supplemented with the mixture of FA and PHBA. Moreover, in cucumber leaves under conditions of the mixture of FA and PHBA, CSY-P13 enhanced the activities of SOD, 
APX, CAT, GSH-Px, DHAR, MDHAR, and GR; increased the transcript levels of $C u / Z n-S O D, M n-S O D$, and CAT; and elevated the contents of AsA and GSH. When CSY-P13 was inoculated into cucumber-planted soil supplemented with the mixture of FA and PHBA, the activities of phosphatase, CAT, urease, and sucrase were increased, and the bacterial richness, diversity, and community composition were affected in rhizospheric soil. Thus, A. calcoaceticus CSY-P13 can degrade the mixture of FA and PHBA in soil and mitigate the stress of FA and PHBA in cucumber by activating antioxidant enzymes and decreasing ROS levels, and also by changing bacterial community in rhizospheric soil and inducing soil enzymes. Antioxidant enzymes in CSY-P13 contribute to the tolerance of this strain to FA and PHBA stress during FA and PHBA degradation.

\section{REFERENCES}

Anupama, V. N., Amrutha, P. N., Chitra, G. S., and Krishnakumar, B. (2008). Phosphatase activity in anaerobic bioreactors for wastewater treatment. Water Res. 42, 2796-2802. doi: 10.1016/j.watres.2008.02.014

Benndorf, D., Loffhagen, N., Härtig, C., and Babel, W. (2004). Growth on phenol at chemostress levels amplifies the expression of the phenol degradation pathway in Acinetobacter calcoaceticus. Eng. Life Sci. 4, 38-42. doi: 10.1002/elsc. 200400014

Bouvet, P. J. M., and Grimont, P. A. D. (1986). Taxonomy of the genus Acinetobacter with the recognition of Acinetobacter baumannii sp. nov., Acinetobacter haemolyticus sp. nov., Acinetobacter johnsonii sp. nov., and Acinetobacter junii sp. nov. and emended descriptions of Acinetobacter calcoaceticus and Acinetobacter lwoffii. Int. J. Syst. Bacteriol. 36, 228-240. doi: 10.1099/00207713-36-2-228

Buck, J. D. (1982). Nonstaining (KOH) method for determination of Gram reactions of marine bacteria. Appl. Environ. Microbiol. 44, 992-993.

Chen, S. Y., Guo, L. Y., Bai, J. G., Zhang, Y., Zhang, L., Wang, Z., et al. (2015). Biodegradation of p-hydroxybenzoic acid in soil by Pseudomonas putida CSYP1 isolated from cucumber rhizosphere soil. Plant Soil 389, 197-210. doi: 10. 1007/s11104-014-2360-x

De, J., Sarkar, A., and Ramaiah, N. (2006). Bioremediation of toxic substances by mercury resistant marine bacteria. Ecotoxicology 15, 385-389. doi: 10.1007/ s10646-006-0066-4

Delneri, D., Degrassi, G., Rizzo, R., and Bruschi, C. V. (1995). Degradation of transferulic and p-coumaric acid by Acinetobacter calcoaceticus DSM586. Biochim. Biophys. Acta 1244, 363-367. doi: 10.1016/0304-4165(95)00021-3

Dong, R., Gu, L., Guo, C., Xun, F., and Liu, J. (2014). Effect of PGPR Serratia marcescens $\mathrm{BC}-3$ and $\mathrm{AMF}$ Glomus intraradices on phytoremediation of petroleum contaminated soil. Ecotoxicology 23, 674-680. doi: 10.1007/s10646014-1200-3

Douglas, L. A., and Bremner, J. M. (1971). A rapid method of evaluating different compounds as inhibitors of urease activity in soils. Soil Biol. Biochem. 3, 309-315. doi: 10.1016/0038-0717(71)90040-X

Elstner, E. F., and Heupel, A. (1976). Inhibition of nitrite formation from hydroxylammoniumchloride: a simple assay for superoxide dismutase. Anal. Biochem. 70, 616-620. doi: 10.1016/0003-2697(76)90488-7

Ferreira, R., Gaspar, H., Gonzalez, J. M., Clara, M. I., and Santana, M. M. (2015). Copper and temperature modify microbial communities, ammonium and sulfate release in soil. J. Plant Nutr. Soil Sci. 178, 953-962. doi: 10.1002/jpln. 201500318

García, C., and Hernández, T. (1997). Biological and biochemical indicators in derelict soils subject to erosion. Soil Biol. Biochem. 29, 171-177. doi: 10.1016/ S0038-0717(96)00294-5

Gawai, K. R., Lokhande, P. D., Kodam, K. M., and Soojhawon, I. (2005). Oxidation of carbonyl compounds by whole-cell biocatalyst. World J. Microbiol. Biotechnol. 21, 457-461. doi: 10.1007/s11274-004-2467-y

\section{AUTHOR CONTRIBUTIONS}

J-GB defined the research theme and designed the methods and experiments. FW wrote the manuscript. Y-QA, YA, and $\mathrm{X}$-JW co-designed the experiments, discussed the analyses, and revised the paper. Z-YC, YZ, XH, C-XC, and LW co-worked on associated data collection and their interpretation.

\section{SUPPLEMENTARY MATERIAL}

The Supplementary Material for this article can be found online at: https://www.frontiersin.org/articles/10.3389/fmicb. 2018.01262/full\#supplementary-material

Gratão, P. L., Monteiro, C. C., Antunes, A. M., Peres, L. E. P., and Azevedo, R. A. (2008). Acquired tolerance of tomato (Lycopersicon esculentum cv. Micro-Tom) plants to cadmium-induced stress. Ann. Appl. Biol. 153, 321-333. doi: $10.1111 / j .1744-7348.2008 .00299 . x$

Guri, A. (1983). Variation in glutathione and ascorbic acid content among selected cultivars of Phaseolus vulgaris prior to and after exposure to ozone. Can. J. Plant Sci. 63, 733-737. doi: 10.4141/cjps83-090

Hollister, E. B., Engledow, A. S., Hammett, A. M., Provin, T. L., Wilkinson, H. H., and Gentry, T. J. (2010). Shifts in microbial community structure along an ecological gradient of hypersaline soils and sediments. ISME J. 4, 829-838. doi: 10.1038/ismej.2010.3

Huang, Y. W., Zhou, Z. Q., Yang, H. X., Wei, C. X., Wan, Y. Y., Wang, X. J., et al. (2015). Glucose application protects chloroplast ultrastructure in heat-stressed cucumber leaves through modifying antioxidant enzyme activity. Biol. Plant. 59, 131-138. doi: 10.1007/s10535-014-0470-1

Karmakar, B., Vohra, R. M., Nandanwar, H., Sharma, P., Gupta, K. G., and Sobti, R. C. (2000). Rapid degradation of ferulic acid via 4-vinylguaiacol and vanillin by newly isolated strain of Bacillus coagulans. J. Biotechnol. 80, 195-202. doi: 10.1016/S0168-1656(00)00248-0

Khongkhaem, P., Suttinun, O., Intasiri, A., Pinyakong, O., and Luepromchai, E. (2016). Degradation of phenolic compounds in palm oil mill effluent by silicaimmobilized bacteria in internal loop airlift bioreactors. Clean Soil Air Water 44, 325-450. doi: 10.1002/clen.201300853

Kim, D., Baik, K. S., Kim, M. S., Park, S. C., Kim, S. S., Rhee, M. S., et al. (2008). Acinetobacter soli sp. nov., isolated from forest soil. J. Microbiol. 46, 396-401. doi: 10.1007/s12275-008-0118-y

Kim, Y. H., Lim, J. H., An, C. H., Jung, B. K., and Kim, S. D. (2012). Soil microbial community analysis using soil enzyme activities in red pepper field treated microbial agents. J. Appl. Biol. Chem. 55, 47-53. doi: 10.3839/jabc.2011.058

Klein, B. P., and Perry, A. K. (1982). Ascorbic acid and vitamin A activity in selected vegetables from different geographical areas of the United States. J. Food Sci. 47, 941-945. doi: 10.1111/j.1365-2621.1982.tb12750.x

Lee, H. J., and Lee, S. S. (2010). Acinetobacter kyonggiensis sp. nov., a $\beta$-glucosidaseproducing bacterium, isolated from sewage treatment plant. J. Microbiol. 48, 754-759. doi: 10.1007/s12275-010-0355-8

Lin, J. (2017). Stress responses of Acinetobacter strain Y during phenol degradation. Arch. Microbiol. 199, 365-375. doi: 10.1007/s00203-016-1310-9

Mukherjee, S. P., and Choudhuri, M. A. (1983). Implications of water stressinduced changes in the levels of endogenous ascorbic acid and hydrogen peroxide in Vigna seedlings. Physiol. Plant. 58, 166-170. doi: 10.1111/j.13993054.1983.tb04162.x

Pagel, J. E., and Seyfried, P. L. (1976). Numerical taxonomy of aquatic Acinetobacter isolates. J. Gen. Microbiol. 96, 220-232. doi: 10.1099/00221287-95-2-220

Pan, X., Zhang, D., Chen, X., Bao, A., and Li, L. (2011). Antimony accumulation, growth performance, antioxidant defense system and photosynthesis of Zea mays in response to antimony pollution in soil. Water Air Soil Pollut. 215, 517-523. doi: 10.1007/s11270-010-0496-8 
Prathibha, K., and Sumathi, S. (2008). Biodegradation of mixture containing monohydroxybenzoate isomers by Acinetobacter calcoaceticus. World J. Microbiol. Biotechnol. 24, 813-823. doi: 10.1007/s11274-007-9545-x

Roberge, M. R. (1978). "Methodology of enzymes determination and extraction," in Soil Enzymes, ed. R. G. Burns (New York, NY: Academic Press), 341-373.

Schinner, F., and Von Mersi, W. (1990). Xylanase, CM-cellulase and invertase activity in soil, an improved method. Soil Biol. Biochem. 22, 511-515. doi: 10.1016/0038-0717(90)90187-5

Sebastian, M., and Ammerman, J. W. (2009). The alkaline phosphatase PhoX is more widely distributed in marine bacteria than the classical PhoA. ISME J. 3, 563-572. doi: 10.1038/ismej.2009.10

Shen, Z., Ruan, Y., Chao, X., Zhang, J., Li, R., and Shen, Q. (2015). Rhizosphere microbial community manipulated by 2 years of consecutive biofertilizer application associated with banana Fusarium wilt disease suppression. Biol. Fertil. Soils 51, 553-562. doi: 10.1007/s00374-015-1002-7

Smirnoff, N. (1993). The role of active oxygen in the response of plants to water deficit and desiccation. New Phytol. 125, 27-58. doi: 10.1111/j.1469-8137.1993. tb03863.x

Sparnins, V. L., Chapman, P. J., and Dagley, S. (1974). Bacterial degradation of 4-hydroxyphenylacetic acid and homoprotocatechuic acid. J. Bacteriol. 120, 159-167.

Tao, K., Liu, X., Chen, X., Hu, X., Cao, L., and Yuan, X. (2017). Biodegradation of crude oil by a defined co-culture of indigenous bacterial consortium and exogenous Bacillus subtilis. Bioresour. Technol. 224, 327-332. doi: 10.1016/j. biortech.2016.10.073

Tardy, V., Spor, A., Mathieu, O., Lévèque, J., Terrat, S., Plassart, P., et al. (2015). Shifts in microbial diversity through land use intensity as drivers of carbon mineralization in soil. Soil Biol. Biochem. 90, 204-213. doi: 10.1016/j.soilbio. 2015.08.010

Turner, J. A., and Rice, E. L. (1975). Microbial decomposition of ferulic acid in soil. J. Chem. Ecol. 1, 41-58. doi: 10.1007/BF00987719

van Spanning, R. J. M., Delgado, M. J., and Richardson, D. J. (2005). "The nitrogen cycle: denitrification and its relationship to $\mathrm{N}_{2}$ fixation," in Nitrogen Fixation in Agriculture, Forestry, Ecology, and the Environment, eds D. Werner and W. E. Newton (Dordrecht: Springer), 277-342. doi: 10.1007/1-4020-3544-6_13

Wan, Y. Y., Zhang, Y., Zhang, L., Zhou, Z. Q., Li, X., Shi, Q., et al. (2015). Caffeic acid protects cucumber against chilling stress by regulating antioxidant enzyme activity and proline and soluble sugar contents. Acta Physiol. Plant. 37:1706. doi: 10.1007/s11738-014-1706-6
Wang, G. L., Wang, L., Chen, H. H., Shen, B., Li, S. P., and Jiang, J. D. (2011). Lysobacter ruishenii sp. nov., a chlorothalonil-degrading bacterium isolated from a long-term chlorothalonil-contaminated soil in China. Int. J. Syst. Evol. Microbiol. 61, 674-679. doi: 10.1099/ijs.0.020990-0

Xu, P. L., Guo, Y. K., Bai, J. G., Shang, L., and Wang, X. J. (2008). Effects of long-term chilling on ultrastructure and antioxidant activity in leaves of two cucumber cultivars under low light. Physiol. Plant. 132, 467-478. doi: 10.1111/ j.1399-3054.2007.01036.x

Xu, S. X., Zhang, S. M., You, X. Y., Jia, X. C., and Wu, K. (2008). Degradation of soil phenolic acids by Phanerochaete chrysosporium under continuous cropping of cucumber. Chin. J. Appl. Ecol. 19, 2480-2484.

Yu, J. Q. (2001). Autotoxic potential of cucurbit crops: phenomenon, chemicals, mechanisms and means to overcome. J. Crop Prod. 4, 335-348. doi: 10.1300/ J144v04n02_15

Zhang, J., Li, D. M., Sun, W. J., Wang, X. J., and Bai, J. G. (2012). Exogenous p-hydroxybenzoic acid regulates antioxidant enzyme activity and mitigates heat stress of cucumber leaves. Sci. Hortic. 148, 235-245. doi: 10.1016/j.scienta.2012. 10.013

Zhang, Y., Wang, X. J., Chen, S. Y., Guo, L. Y., Song, M. L., Feng, H., et al. (2015). Bacillus methylotrophicus isolated from the cucumber rhizosphere degrades ferulic acid in soil and affects antioxidant and rhizosphere enzyme activities. Plant Soil 392, 309-321. doi: 10.1007/s11104-015-2 464-y

Zhou, X., Yu, G., and Wu, F. (2012). Soil phenolics in a continuously monocropped cucumber (Cucumis sativus L.) system and their effects on cucumber seedling growth and soil microbial communities. Eur. J. Soil Sci. 63, 332-340. doi: 10.1111/j.1365-2389.2012.01442.x

Conflict of Interest Statement: The authors declare that the research was conducted in the absence of any commercial or financial relationships that could be construed as a potential conflict of interest.

Copyright (c) 2018 Wu, An, An, Wang, Cheng, Zhang, Hou, Chen, Wang and Bai. This is an open-access article distributed under the terms of the Creative Commons Attribution License (CC BY). The use, distribution or reproduction in other forums is permitted, provided the original author(s) and the copyright owner are credited and that the original publication in this journal is cited, in accordance with accepted academic practice. No use, distribution or reproduction is permitted which does not comply with these terms. 